\title{
Gene losses in the common vampire bat illuminate molecular adaptations to blood feeding
}

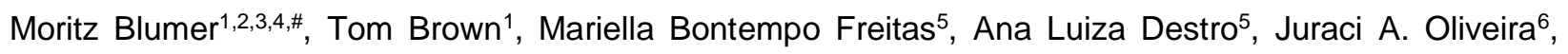
Ariadna Morales ${ }^{4,7,8}$, Tilman Schell ${ }^{7,8}$, Carola Greve ${ }^{7,8}$, Martin Pippel ${ }^{1}$, David Jebb ${ }^{1,2,3}$, Nikolai Hecker ${ }^{1,2,3}$, Alexis-Walid Ahmed ${ }^{4,7,8}$, Bogdan Kirilenko ${ }^{4,7,8}$, Maddy Foote ${ }^{9}$, Axel Janke ${ }^{7,10}$, Burton K. Lim ${ }^{11}$ and Michael Hiller ${ }^{1,2,3,4,7,8,{ }^{*}}$

${ }^{1}$ Max Planck Institute of Molecular Cell Biology and Genetics, 01307 Dresden, Germany.

${ }^{2}$ Max Planck Institute for the Physics of Complex Systems, 01187 Dresden, Germany.

${ }^{3}$ Center for Systems Biology Dresden, 01307 Dresden, Germany.

${ }^{4}$ Goethe-University, Faculty of Biosciences, Max-von-Laue-Str. 9, 60438 Frankfurt, Germany

${ }^{5}$ Federal University of Viçosa, Department of Animal Biology, Viçosa, Brazil

${ }^{6}$ Federal University of Viçosa, Department of General Biology, Viçosa, Brazil

${ }^{7}$ LOEWE Centre for Translational Biodiversity Genomics, Senckenberganlage 25, 60325 Frankfurt,

Germany

${ }^{8}$ Senckenberg Research Institute, Senckenberganlage 25, 60325 Frankfurt, Germany

${ }^{9}$ Native Bat Conservation Program, Toronto Zoo, 361A Old Finch Avenue, Toronto, Canada

10 Senckenberg Biodiversity and Climate Research Centre, Senckenberganlage 25, 60325 Frankfurt am Main, Germany

${ }^{11}$ Royal Ontario Museum, Department of Natural History, 100 Queen's Park, M5S 2C6 Toronto, Ontario, Canada

\# Present address: Department of Genetics, University of Cambridge, Downing Street, CB2 3EH Cambridge, UK

*To whom correspondence should be addressed:

Michael Hiller

LOEWE Centre for Translational Biodiversity Genomics, Senckenberganlage 25, 60325 Frankfurt, Germany

Tel: +49 69 7542-1398

E-Mail: Michael.Hiller@senckenberg.de 


\begin{abstract}
Feeding exclusively on blood, vampire bats represent the only obligate sanguivorous lineage among mammals. To uncover genomic changes associated with adaptations to this unique dietary specialization, we generated a new haplotype-resolved reference-quality genome of the common vampire bat (Desmodus rotundus) and screened 26 bat species for genes that were specifically lost in the vampire bat lineage. We discovered previously-unknown gene losses that relate to metabolic and physiological changes, such as reduced insulin secretion (FFAR1, SLC30A8), limited glycogen stores (PPP1R3E), and a distinct gastric physiology (CTSE). Other gene losses likely reflect the biased nutrient composition (ERN2, CTRL) and distinct pathogen diversity of blood (RNASE7). Interestingly, the loss of REP15 likely helped vampire bats to adapt to high dietary iron levels by enhancing iron excretion and the loss of the 24S-hydroxycholesterol metabolizing enzyme CYP39A1 could contribute to their exceptional cognitive abilities. Finally, losses of key cone phototransduction genes (PDE6H, PDE6C) suggest that these strictly-nocturnal bats completely lack cone-based vision. These findings enhance our understanding of vampire bat biology and the genomic underpinnings of adaptations to sanguivory.
\end{abstract}




\section{Introduction}

Vampire bats are the only obligate sanguivorous lineage among tetrapods ${ }^{1}$. This exceptional dietary specialization is reflected in all aspects of their biology, including morphology, physiology and behavior ${ }^{2,3}$. To detect prey, the common vampire bat (Desmodus rotundus) exhibits a well-developed olfactory system ${ }^{4}$, advanced low-frequency hearing abilities ${ }^{5}$ and, unique among mammals, the ability to sense infrared radiation ${ }^{6}$. Compared to other bats, vampire bats have exceptional terrestrial locomotion skills to sneak up on their prey ${ }^{7}$. Razor-sharp enamel-less upper incisors help cutting through the prey's skin and anticoagulants in their saliva prevent the prey's blood from coagulating during feeding ${ }^{8,9}$.

As the sole nutritional source, blood represents a challenging diet for several reasons. First, blood has a high fluid content of $78 \%$ and a comparatively low caloric value, making it necessary for a vampire bat to ingest as much as 1.4 times their body weight in blood during a single meal ${ }^{10,11}$. To enable the ingestion of large amounts of blood, their stomach experienced a functional shift towards a distensible organ primarily engaged in storage and fluid absorption ${ }^{12}$. Second, blood has a high iron content compared to other diets, which mainly stems from hemoglobin-derived heme and ferric iron transported by transferrin ${ }^{13-15}$. Third, the dry mass of blood has a highly skewed nutritional composition, providing mostly proteins (93\%) with very little lipids and carbohydrates (1\% each) ${ }^{11}$.

Due to a low carbohydrate intake, vampire bats exhibit lower basal insulin levels than other mammals ${ }^{10,11,16}$. Similar to human type 2 diabetes patients, vampire bats feature a reduced glucose-stimulated insulin secretion response, resulting in hyperglycemia upon an experimental glucose overload ${ }^{16}$. Glycogen and lipid stores are also reduced in vampire bats, which contributes to their fasting vulnerability and early deaths after 48-72 $\mathrm{h}$ of fasting ${ }^{17,18}$. To compensate for their fasting vulnerability, vampire bats share regurgitated blood with roost mates that failed to obtain a nightly meal ${ }^{19,20}$.

To gain insights into the molecular basis of vampire bat adaptations to sanguivory, comparative studies using the genome of the common vampire bat detected signatures of selection in genes involved in responses to nutrient starvation, metabolism, nitrogen waste disposal, the coagulation cascade, and immunity ${ }^{21,22}$. Common vampire bats have fewer TAS2R taste receptor genes than other bats, indicating a reduced sense of bitter taste reception ${ }^{23,24}$. In addition to genetic changes, vampire bats also possess a gut microbiome very different from that of other bats, and genes encoded by their gut microbiome further contribute to meeting the challenges of sanguivory ${ }^{21}$. Despite these advances, our understanding of which genomic changes are important for adaptations to sanguivory remains incomplete.

A limitation of previous comparative studies was the restricted taxonomic representation. For example, Zepeda Mendoza et al. ${ }^{21}$ compared the $D$. rotundus genome to nine other bat genomes, with $D$. rotundus as the only representative of Phyllostomidae bats (Figure 1A). With this limited taxonomic resolution one cannot differentiate between those genomic changes that are shared between all phyllostomid bats (comprising more than 200 species) and those changes that evolved specifically in the vampire bat lineage and thus could be relevant for adaptations to sanguivory. To uncover genomic changes that evolved specifically in the vampire bat lineage, we generated a state-of-the-art haplotype-resolved chromosomelevel assembly of $D$. rotundus and made use of many additional phyllostomid genomes that include the 
closest sister species of vampire bats (Supplementary Table 1). Since the loss of ancestral genes can be an important evolutionary force and previous studies revealed many associations between gene losses and phenotypic differences, including dietary adaptations ${ }^{25-29}$, we conducted a genome-wide screen for genes that are specifically lost in $D$. rotundus and that lack inactivating mutations in 25 other bat species. This screen revealed 3 known and 10 previously-unknown gene losses. Many of these novel gene losses have clear associations with vampire bat traits and some gene losses may contribute to coping with the challenges imposed by sanguivory.

\section{Results}

\section{A new haplotype-resolved reference-quality $D$. rotundus assembly}

To perform an accurate and comprehensive screen for gene losses in the common vampire bat, a genome assembly with high completeness, contiguity and base accuracy is desirable. The existing Illumina assembly of the common vampire bat ${ }^{21}$ has more than 50,000 assembly gaps, indicating that a subset of genes will have missing sequences. This assembly also exhibits base errors that mimic gene-inactivating mutations, including cases where multiple putative mutations in the same gene are all erroneous (Supplementary Figure 1). Therefore, we generated a new reference-quality $D$. rotundus assembly. We used $\mathrm{PacBio}$ circular consensus $(\mathrm{HiFi})$ sequencing ${ }^{30}$ to produce $32 \mathrm{X}$ coverage in reads with an average length of $9.1 \mathrm{~kb}$ and used the Dovetail Omni-C protocol to produce $67 \mathrm{X}$ coverage of chromosome conformation capture Illumina read pairs. With these data, we obtained two haplotype-resolved chromosome-level assemblies that have only 596 and 557 assembly gaps, contig N50 values of 6.85 and $7.98 \mathrm{Mb}$ and scaffold $\mathrm{N} 50$ values of 160.1 and $160.1 \mathrm{Mb}$ (Figure 1A, Supplementary Table 1). The contig N50 metric is $~ 90$-times higher than that of the Illumina-based $D$. rotundus assembly ${ }^{21}$. The karyotype of D. rotundus is $2 \mathrm{n}=28^{31}$. All 13 autosome pairs are represented by chromosome-level scaffolds (Figure 1B). Haplotype 1 contains the $X$ chromosome as an additional chromosome-level scaffold. Haplotype 2 contains the $\mathrm{Y}$ chromosome, which was assembled as several scaffolds. Overall, more than $96 \%$ of both haplotypes are contained in chromosome-level scaffolds (Figure 1B). Using Merqury ${ }^{32}$, we estimated a very high base accuracy of QV 64.2 and 64.5 for both haplotypes, indicating one error per $\sim 2.6$ million base pairs.

To systematically assess gene completeness among the $D$. rotundus and other available bat genomes, we applied TOGA (Tool to infer Orthologs from Genome Alignments), a method that infers orthologs from whole genome alignments ${ }^{33}$, to 18,430 ancestral placental mammal coding genes (Methods). In comparison to the Illumina $D$. rotundus assembly, the number of ancestral genes with missing sequences dropped from 1,841 to 128 in our combined haplotype assemblies, whereas the number of genes with an intact reading frame increased from 15,295 to 17,301 (Supplementary Table 1). This indicates a substantially higher gene completeness in our assemblies, similar to the most contiguous bat assemblies generated to date ${ }^{34}$ (Figure 1C). 
bioRxiv preprint doi: https://doi.org/10.1101/2021.10.18.462363; this version posted October 19, 2021. The copyright holder for this preprint (which was not certified by peer review) is the author/funder, who has granted bioRxiv a license to display the preprint in perpetuity. It is made available under aCC-BY-ND 4.0 International license.

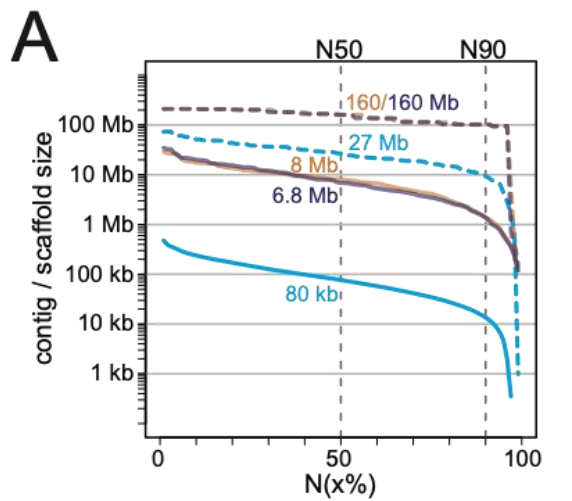

- contig ---scaffold
- Illumina / Chicago (Zepeda Mendoza et al.)
- PacBio HiFi / OmniC haplotype 1
- PacBio HiFi / OmniC haplotype 2

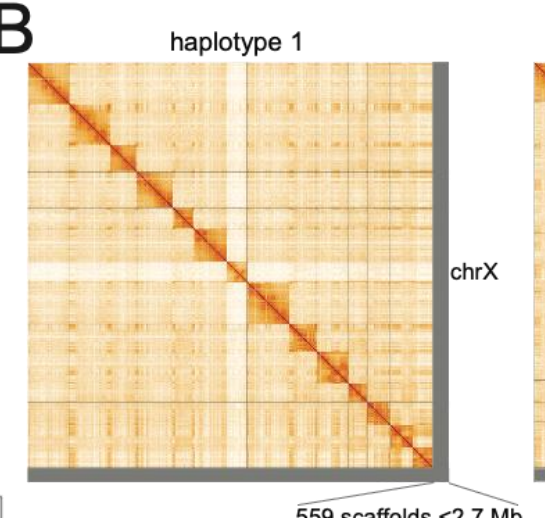

559 scaffolds $<2.7 \mathrm{Mb}$

$78.6 \mathrm{Mb}=3.7 \%$ of assembly

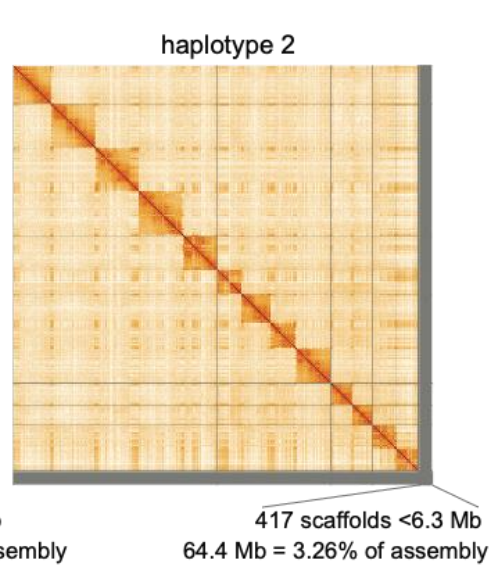

C

TOGA status of 18430 ancestral placental mammal genes (17682 without chrX)
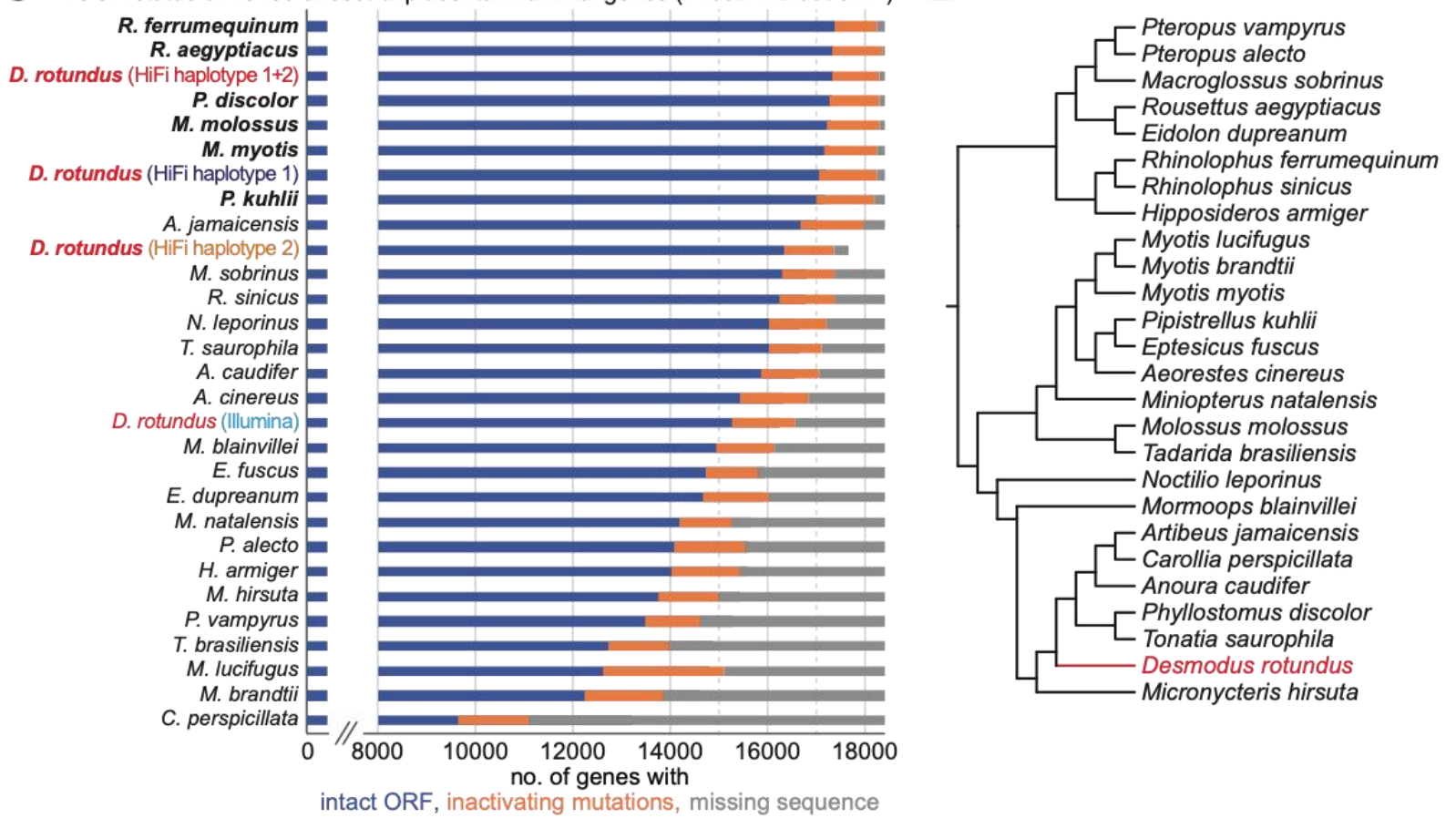

Figure 1: Haplotype-resolved chromosome-level assembly of Desmodus rotundus.

(A) Comparison of assembly contiguity between our haplotype-resolved assemblies and the previous lllumina-based assembly ${ }^{21}$. The graph shows contig (solid lines) and scaffold (dashed lines) sizes at the $\mathrm{Y}$-axis, for which $\mathrm{x}$ per cent of the assembly consists of contigs and scaffolds of at least that size.

(B) HiC contact maps show 14 and 13 chromosome-level scaffolds for haplotype 1 and 2 that each comprise more than $96 \%$ of the respective haplotype assembly. Haplotype 1 contains the $X$ chromosome. The $Y$ chromosome is part of haplotype 2 and assembled into several shorter scaffolds.

(C) Status of 18,430 ancestral placental mammal genes in each assembly, as inferred by TOGA. Genes are classified into those that have an intact reading frame (blue), have inactivating mutations (orange) or have missing coding parts due to assembly gaps or fragmentation (grey). Assemblies are sorted by the number of intact genes. Long readbased assemblies (bold font) consistently exhibit more intact genes and fewer missing genes compared to short readbased assemblies (not bold). For the $D$. rotundus haplotype 2 assembly that does not contain the $\mathrm{X}$ chromosome, we excluded genes located on the $X$ chromosome and only considered the remaining 17,682 genes. To provide a fair comparison with previous assemblies that collapse both haplotypes, we also computed statistics for the union of both $D$. rotundus haplotype assemblies (haplotype $1+2$ ), which exhibits the third highest number of intact genes of all included genomes.

(D) Phylogeny of the bats analyzed in this study ${ }^{1,42,43}$. 


\section{A genome-wide screen revealed known and novel vampire bat-specific gene losses}

To detect genes that were specifically lost in the vampire bat lineage, we used our two haplotype assemblies and considered 25 other bat genomes ${ }^{21,23,34-41}$ (http://dnazoo.org/), including Micronycteris hirsuta and Phyllostomus discolor, which represent the closest phylogenetic outgroup and sister lineages of vampire bats, respectively ${ }^{1,42,43}$ (Figure 1D). Using the human gene annotation as the reference, we applied TOGA to detect genes that exhibit gene-inactivating mutations (premature stop codons, frameshifts, splice site disruptions, and deletions of exons or entire genes) specifically in $D$. rotundus.

This screen revealed 13 vampire bat-specific gene losses. Three of these losses have been reported before: the sweet taste receptor gene TAS1R2 ${ }^{44}$ and the bitter taste receptor genes TAS2R5 and TAS2R42 24 . These gene losses indicate a reduced sense of taste reception in vampire bats. To our knowledge, the remaining 10 gene losses (REP15, FFAR1, SLC30A8, PPP1R3E, CTSE, ERN2, CTRL, CYP39A1, PDE6H, RNASE7) have not been reported before.

The inactivating mutations in these 10 genes are displayed in Figure $2 \mathrm{~A}$. In support of the validity of the underlying mutations, the 10 gene losses are also detected in the Illumina $D$. rotundus assembly and exhibit at least one shared inactivating mutation that is supported by both PacBio HiFi and Illumina reads. Further supporting gene loss, selection rate analysis using RELAX ${ }^{45}$ showed that 9 of the 10 genes evolve under relaxed selection in $D$. rotundus to preserve the reading frame (significant for 7 of 9 genes, Supplementary Table 2). Finally, inspecting available $D$. rotundus RNA-seq data, we either found no relevant expression in tissues where expression would be expected or found that the aligned reads supported the geneinactivating mutations, indicating that potential transcripts cannot be translated into a full length protein (Supplementary Figure 2).

Intriguingly, as detailed below, the loss of these genes in the common vampire bat relates to a number of adaptations to their highly specialized blood diet, such as reduced insulin secretion and glycogen synthesis and a distinct stomach physiology (Figure 2B). These gene losses further provide a possible mechanism contributing to vampire bats' exceptional social behavior, and indicate the complete lack of cone photoreceptor function in $D$. rotundus. 
bioRxiv preprint doi: https://doi.org/10.1101/2021.10.18.462363; this version posted October 19, 2021. The copyright holder for this preprint (which was not certified by peer review) is the author/funder, who has granted bioRxiv a license to display the preprint in perpetuity. It is made available under aCC-BY-ND 4.0 International license.

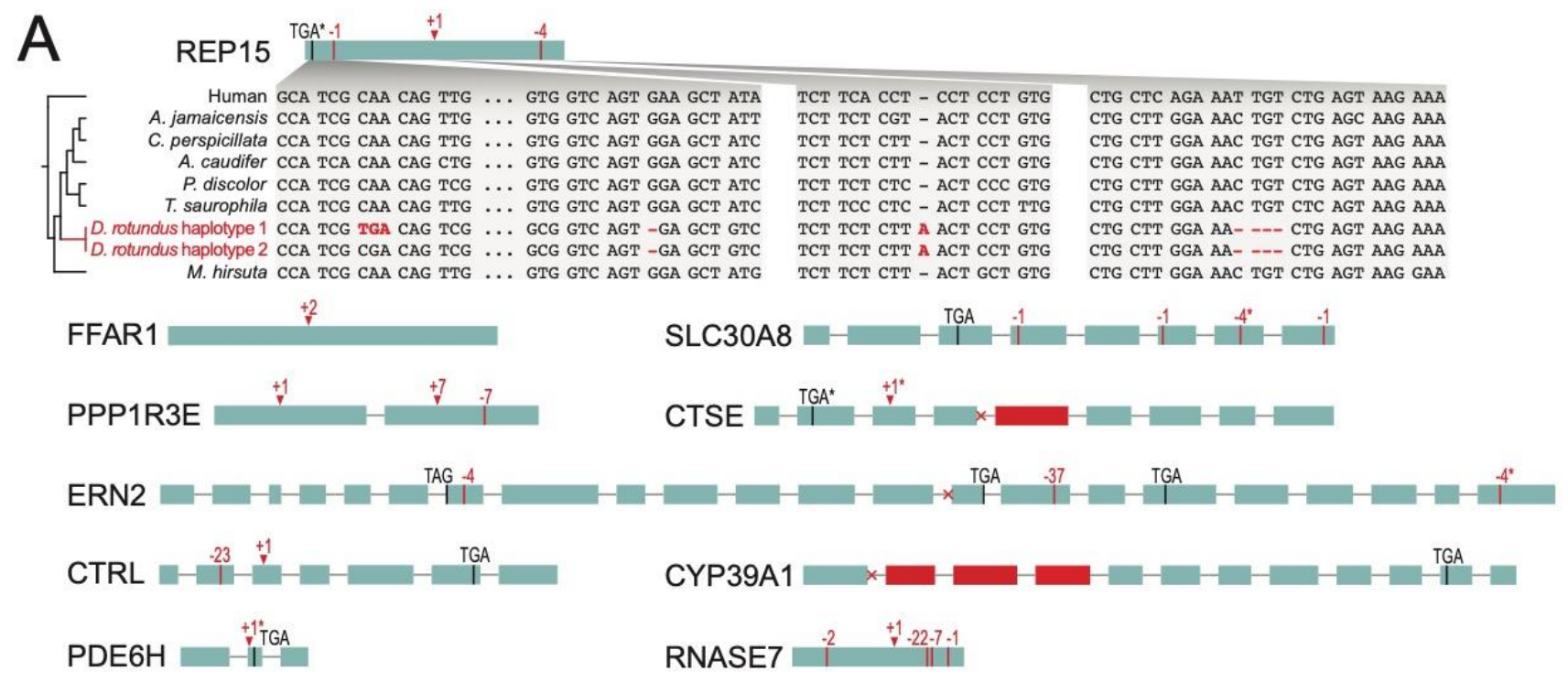

B

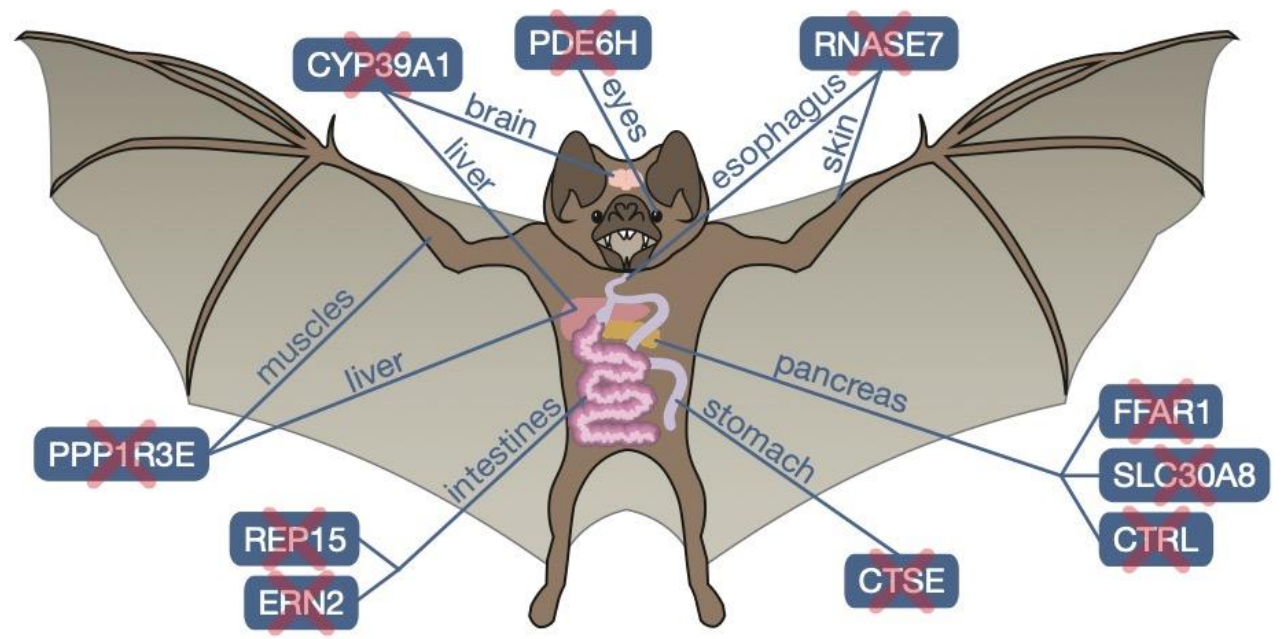

Figure 2: Inactivating mutations and affected organ systems of 10 previously-unknown vampire bat-specific gene losses. (A) Exon-intron structure visualization with inactivating mutations that are detected in the Desmodus rotundus genome. Premature stop codons are shown as black vertical lines, frameshifting deletions as red vertical lines and frameshifting insertions as red arrow heads. Donor or acceptor splice site mutations are indicated as a cross at the exon boundaries. Deleted exons are in red. Asterisks denote mutations that are heterozygous in our sequenced $D$. rotundus individual (present in only one of the two haplotype assemblies). The inset for REP15 illustrates that inactivating mutations and thus gene loss was only detected in the common vampire bat.

(B) Illustration of organs and anatomical sites where the 10 genes play important roles. 


\section{Loss of REP15 and enhanced iron excretion}

The loss of REP15 (RAB15 effector protein), a gene involved in regulating cellular iron uptake ${ }^{46}$, is likely related to the obligatory iron-rich blood diet of vampire bats. Despite the importance of iron for various cellular processes, iron overload can have severe detrimental effects ${ }^{15}$. Remarkably, the common vampire bat tolerates extreme dietary iron levels without exhibiting adverse effects ${ }^{47}$ - the relative amount of dietary iron was estimated to be 800 -fold higher compared to humans ${ }^{13}$. However, blood iron concentration in vampire bats has never been determined to our knowledge. Therefore, we measured whole blood iron concentrations in wild $D$. rotundus and compared it to two other neotropical bats (Supplementary Table 3). We found that blood iron content was significantly higher in the common vampire bat compared to the fruiteating bat Artibeus lituratus (family Phyllostomidae; t-test: $\mathrm{P}=0.01$, Figure $3 \mathrm{~A}$ ). Vampire bats also had higher blood iron levels compared to the insectivorous outgroup bat Myotis myotis (family Vespertilionidae; not significant, likely due to the small sample size of four individuals; Figure $3 \mathrm{~A}$ ). This suggests that vampire bats would benefit from mechanisms to lower systemic iron levels.

REP15 is specifically expressed in the gastrointestinal tract ${ }^{48}$ (Figure 3B). Cellular overexpression of REP15 decreases the amount of iron-transporting transferrin receptors on the cell surface ${ }^{46}$ (Figure 3C). Since transferrin receptor availability is a limiting factor for cellular iron uptake ${ }^{49}, R E P 15$ likely inhibits the uptake of iron from the bloodstream into gastrointestinal cells. Consistent with this inhibitory effect, the downregulation of REP15 in colorectal cancer cells coincides with increased intracellular iron levels in these cells ${ }^{50,51}$.

Why is a gene that inhibits cellular iron uptake specifically lost in $D$. rotundus? We propose that $R E P 15$ loss represents a strategy to boost iron excretion and thus helps vampire bats to reduce systemic iron levels. Loss of REP15 is expected to enhance the accumulation of iron in cells of the gastrointestinal tract, where it is specifically expressed. Because the intestinal epithelium has a relatively fast turnover time ${ }^{52}$, iron is subsequently eliminated by shedding iron-containing gastrointestinal cells. This general mechanism has been recently suggested as an important factor controlling iron loss in mammals ${ }^{53}$.

Intriguingly, a 1980 study on the distribution of iron in the gastrointestinal tract of $D$. rotundus made observations that precisely match this hypothesis ${ }^{13}$. Using histochemical staining techniques along with electron microscopy and radiography, large accumulations of iron in ferritin-containing vacuoles were identified in gastrointestinal epithelial cells that frequently desquamated into the intestinal lumen ${ }^{13}$ (Figure $3 D, E)$. This observation is consistent with enhanced cellular iron uptake in gastrointestinal cells of vampire bats to which REP15 loss could contribute. In addition to enhanced excretion, a previous study found that vampire bats limit gastrointestinal iron absorption by increased expression of hepcidin, a factor that inhibits intestinal iron absorption ${ }^{47}$. Furthermore, iron-storing ferritin genes are expanded in the common vampire bat genome ${ }^{21}$ and these bats have high levels of iron-binding RFESD in the serum proteome ${ }^{54}$. Thus, limited iron absorption (mediated by increased hepcidin expression), a higher capacity for iron storage (mediated by ferritin and RFESD), and enhanced iron excretion (mediated by inactivating the inhibitory factor REP15) help vampire bats to cope with their iron-rich diet. 
bioRxiv preprint doi: https://doi.org/10.1101/2021.10.18.462363; this version posted October 19, 2021. The copyright holder for this preprint (which was not certified by peer review) is the author/funder, who has granted bioRxiv a license to display the preprint in perpetuity. It is made

A

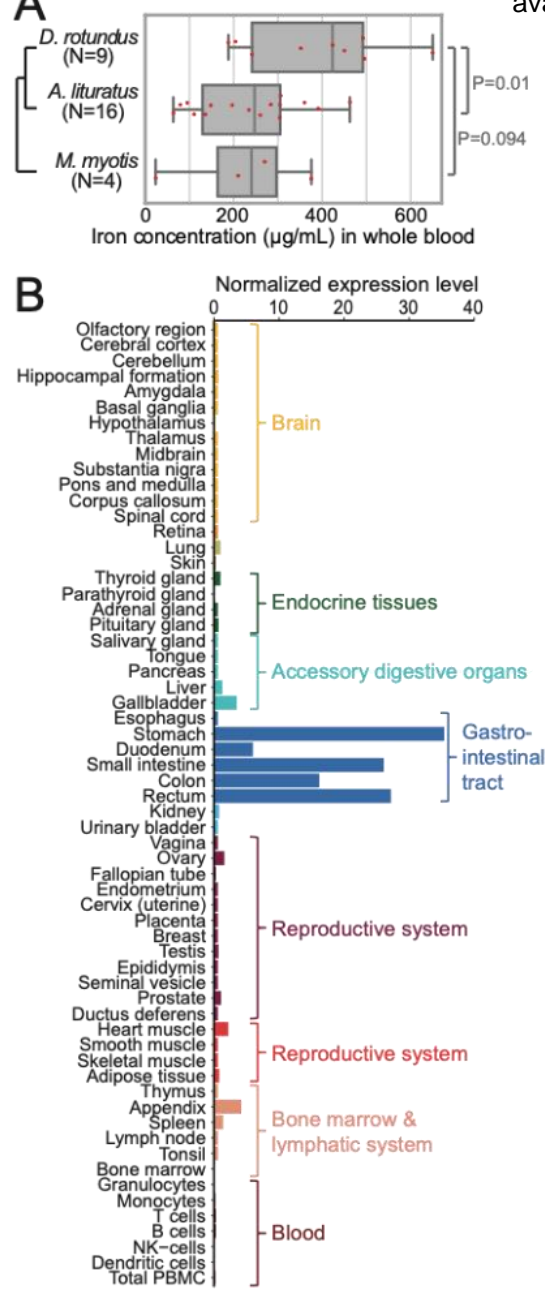

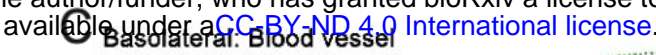

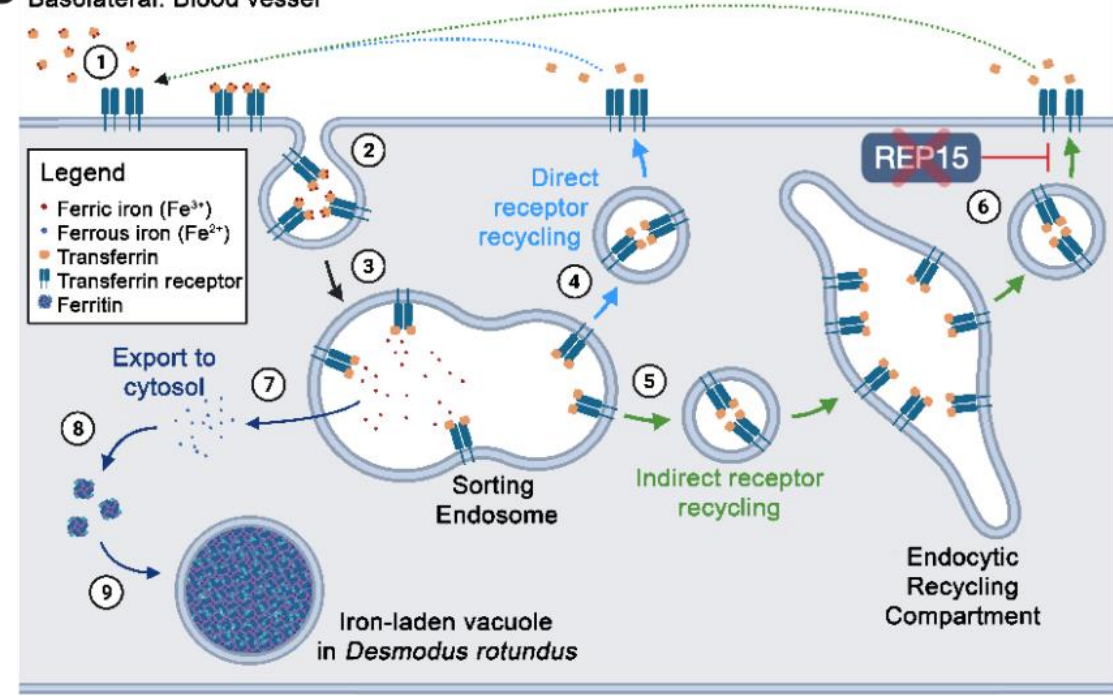

Apical: Gastrointestinal Lumen

$D$

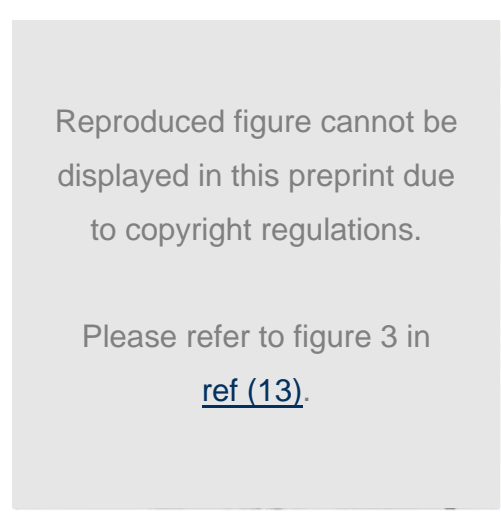

\section{$E$}

$$
\begin{aligned}
& \text { Reproduced figure cannot be } \\
& \text { displayed in this preprint due } \\
& \text { to copyright regulations. } \\
& \text { Please refer to figure } 8 \text { in } \\
& \underline{\text { ref }(13)} .
\end{aligned}
$$

Figure 3: Loss of REP15 in Desmodus rotundus and enhanced iron excretion.

(A) Measurements of iron concentration in whole blood of $D$. rotundus, Artibeus lituratus and Myotis myotis show that vampire bats have higher circulatory iron levels. P-values are computed with a two-sided t-test.

(B) REP15 mRNA expression is highest in gastrointestinal tract tissues. Data was taken from the Human Protein Atlas ${ }^{48}$ (https://www.proteinatlas.org/ENSG00000174236-REP15/tissue) and show the consensus RNA expression values that integrate three gene expression datasets.

(C) Illustration of transferrin receptor-mediated cellular iron uptake and function of REP15 in intestinal epithelial cells. Transferrin, an abundant ferric iron-binding plasma protein, binds to transferrin receptors that are present only in the basolateral membrane (1). Transferrin-transferrin receptor complexes are internalized via endocytosis (2). In sorting endosomes, ferric iron is released (3) and the unladen complexes are either directly targeted back to the cell membrane (4) or sent to the endocytic recycling compartment (5). REP15, encoded by the gene that is lost in $D$. rotundus, specifically localizes to the endocytic recycling compartment (6) and inhibits recycling of the unladen complex to the cell membrane ${ }^{46}$, where transferrin and its receptor dissociate and the released transferrin can bind ferric iron again. Because the availability of transferrin receptors on the cell surface limits iron uptake ${ }^{49}$, the presence of REP15 normally inhibits cellular iron uptake. In the sorting endosome, ferric iron $\left(\mathrm{Fe}^{3+}\right)$ is reduced to ferrous iron $\left(\mathrm{Fe}^{2+}\right)$ and exported to the cytosol (7), where ferritin acts as the major high-capacity iron storage protein (8). Interestingly, accumulations of ferritin and other "ferruginous" complexes enclosed in vacuoles were observed in intestinal epithelial cells of $D$. rotundus (9, panel D). Loss of REP15 likely enhances iron accumulation in intestinal epithelial cells and shedding of these cells boosts iron excretion in $D$. rotundus.

(D) Light microscopy image, reproduced from Figure 3 in ${ }^{13}$, showing a longitudinal section of the upper villus half from the D. rotundus ileum. Prussian blue staining that indicates iron demonstrates the presence of iron-containing cytoplasmic granules in epithelial cells (arrow). In addition to delivering iron via the bloodstream, a macrophage-linked mechanism contributes to iron deposition in these epithelial cells ${ }^{13}$.

(E) Prussian blue-positive granules are present in the forming feces of $D$. rotundus, showing that these bats excrete iron by shedding iron-containing intestinal cells. The figure is reproduced from Figure 8 in ${ }^{13}$. 


\section{Losses of FFAR1 and SLC30A8 and reduced insulin secretion}

FFAR1 (free fatty acid receptor 1 ) encodes a $G$ protein-coupled receptor that is highly expressed in pancreatic beta cells and senses medium to long chain free fatty acids ${ }^{48,55}$. Free fatty acids augment glucose-stimulated insulin secretion and FFAR1 is a major factor that mediates this effect ${ }^{55,56}$ (Figure 4). Glucose-stimulated insulin secretion involves an initial, rapid phase, which appears to be largely dependent on the depletion of an existing pool of membrane-docked insulin secretory granules, and a second, prolonged phase, which requires the production of new granules to supply the ongoing secretion process 55,57 . Deletion of FFAR1 in mice reduces the amplifying effect of free fatty acids in the prolonged phase by $\sim 50 \% 56,58$. Consistent with this, FFAR1 expression levels in human islets positively correlate with insulin secretion, which suggested that FFAR1 deficiency could lower the insulin secretory capacities of beta cells and thus contribute to the development of type 2 diabetes ${ }^{59,60}$. In addition to directly stimulating insulin secretion in beta cells, FFAR1 also amplifies insulin secretion indirectly ${ }^{55}$. First, FFAR1 is expressed in enteroendocrine cells, where its activation triggers the release of incretin hormones that stimulate pancreatic insulin secretion ${ }^{61}$. Second, FFAR1 is expressed in the brain and likely functions as a lipid sensor that influences insulin secretion through innervation of pancreatic islets ${ }^{62}$. Hence, FFAR1 amplifies insulin secretion via multiple mechanisms.

The free fatty acid sensor FFAR1 likely became dispensable for vampire bats for two reasons. First, the FFAR1 ligand (fatty acids) is barely present in their blood diet. Second, the low dietary sugar content likely abolishes the need for a normal glucose-stimulated insulin secretion, including the prolonged insulin secretion phase to which FFAR1 substantially contributes. Indeed, vampire bats exhibit lower basal insulin levels than other mammals and show a substantially reduced insulin secretion with prolonged hyperglycemia upon an experimental glucose overload ${ }^{10,11,16}$. While having similarities to the defective insulin secretion response in human type 2 diabetes patients, in vampire bats, this is likely an adaptation to prevent hypoglycemia, since glucose must remain in the bloodstream. Whereas a previous study detected signatures of positive selection in FFAR1 and interpreted it as a means to improve glucose utilization in $D$. rotundus ${ }^{21}$, our analysis reveals that FFAR1 is actually lost and suggests that this gene loss relates to reduced insulin secretion under normal conditions and the inability to cope with high glucose intake when experimentally challenged.

SLC30A8 (solute carrier family 30 member 8) encodes the most highly expressed zinc transporter in pancreatic beta cells ${ }^{63,64}$. In secretory granules of beta cells, zinc is required for the formation of zinc-insulin hexamers (Figure 4), which protect insulin from degradation ${ }^{65,66}$. Therefore, loss of the zinc transporter $S L C 30 A 8$ may have been a consequence of or may contribute to the decreased insulin secretion phenotype of $D$. rotundus.

Another, not mutually exclusive hypothesis is that SLC30A8 loss in vampire bats may be beneficial by reducing the requirements for body zinc levels. Even though sufficient dietary zinc is available from mammalian blood 67,68 , it might not be efficiently absorbed by vampire bats, since high dietary iron concentrations can inhibit zinc absorption ${ }^{69}$ and zinc in turn stimulates iron absorption in intestinal cells ${ }^{70}$. Since blood has a high iron:zinc ratio of $66: 1^{67}$, high dietary iron levels could induce zinc deficiency in vampire bats. Interestingly, SLC30A8 knockout in mice causes extremely low zinc concentrations in beta cells ${ }^{71}$. Similarly, "natural SLC30A8 knockouts" in mammalian herbivores such as guinea pig, sheep and 
cow that also lost this gene ${ }^{72}$ are associated with low pancreatic islet zinc concentrations ${ }^{73-75}$. Since beta cells are normally among the cell types with the highest zinc concentration ${ }^{76}$, it is possible that these herbivores may have lost $S L C 30 A 8$ because vegetarian diets are generally more limited in zinc content 77,78. Repeated loss of $S \angle C 30 A 8$ in the vampire bat and in herbivorous mammals could therefore represent a strategy to restrict zinc utilization to other essential physiological functions. A precondition for this strategy would be that insulin stability and secretion does not depend on zinc anymore, as shown in guinea pigs, or that insulin secretion would not be essential anymore, as it seems to be the case for vampire bats.

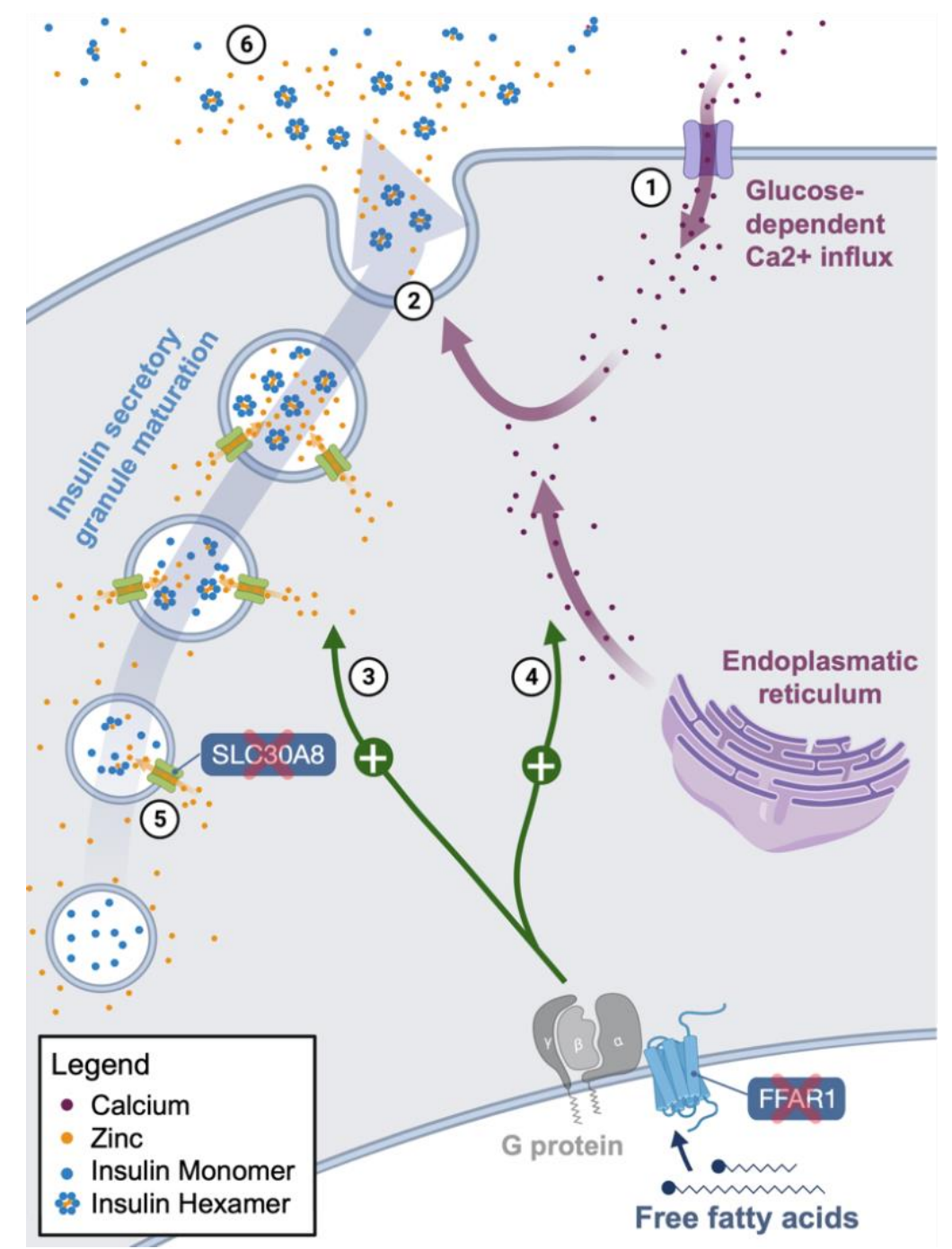

Figure 4: Losses of SLC30A8 and FFAR1 in Desmodus rotundus relate to reduced insulin secretion.

Illustration of the roles of both genes in insulin synthesis and secretion in pancreatic beta cells. Glucose-stimulated insulin secretion is initiated by the opening of voltage-gated calcium channels (1) ${ }^{55}$. The resulting influx of calcium enhances insulin secretion by stimulating exocytosis of insulin secretory granules (2). FFAR1 encodes a G proteincoupled receptor that upon activation enhances the prolonged insulin secretion phase via (F)-actin remodeling (3). FFAR1 also triggers the release of calcium from the endoplasmic reticulum (4), which adds to the glucose stimulated calcium influx and amplifies exocytosis of secretory granules. SLC30A8 transports zinc into maturing insulin secretory granules, where zinc is essential for the formation of insulin hexamers (5). Upon secretion, these hexamers dissociate, releasing bioactive insulin monomers and zinc into the circulation (6). Loss of FFAR1 and SLC3OA8 in D. rotundus is likely related to vampire bats' reduced insulin secretion. 


\section{Loss of PPP1R3E and impaired glycogen metabolism}

PPP1R3E (protein phosphatase 1 regulatory subunit 3E) encodes a regulatory subunit of protein phosphatase 1 (PP1) ${ }^{79}$. PP1 plays a central role in regulating a switch between synthesis and breakdown of glycogen, the major short-term storage form of glucose ${ }^{80}$. By dephosphorylating glycogen synthase, PP1 activates this enzyme and promotes glycogen synthesis ${ }^{81}$. By dephosphorylating glycogen phosphorylase, PP1 inhibits this enzyme and consequently glycogen breakdown ${ }^{81}$ (Supplementary Figure $3 A)$. The activity of PP1 depends on a regulatory subunit, which is encoded by seven different genes with different expression patterns (PPP1R3A - PPP1R3G) ${ }^{79}$. These regulatory subunits are critical for PP1 activity as overexpression of $P P P 1 R 3 A, P P P 1 R 3 B, P P P 1 R 3 C$, or PPP1R3G in cellular or animal models increases glycogen content, whereas their knockout reduces glycogen content ${ }^{82-86}$. Even though no animal studies of PPP1R3E exist, the gene is transcriptionally regulated by insulin and PPP1R3E binds to glycogen 79. Thus, PPP1R3E most likely functions like the other glycogen-targeting subunits. With the exception of $P P P 1 R 3 E$ loss in $D$. rotundus, none of the seven regulatory subunit-encoding genes exhibit inactivating mutations in any analyzed bat (Supplementary Figure 3B).

The specific loss of PPP1R3E likely relates to the low glycogen concentrations in $D$. rotundus ${ }^{17}$. In fact, fed vampire bats have hepatic glycogen stores that are $\sim 85 \%$ smaller than in fruit-eating bats and $\sim 60 \%$ smaller than in other mammals fed on high-protein diets ${ }^{17}$. Since sufficient glycogen stores are important to withstand periods of fasting, loss of PPP1R3E and the associated smaller glycogen stores may also contribute to the observed starvation vulnerability of vampire bats.

\section{Loss of CTSE and altered stomach function}

The loss of CTSE (cathepsin E) in D. rotundus may be a consequence of extensive morphological and physiological modifications of their stomach, which is unparalleled by any other mammalian species ${ }^{12,87}$. Most notably, the stomach of $D$. rotundus experienced fundamental remodeling from a compact muscular organ involved in mechanical and chemical digestion towards a distensible structure that functions primarily to store large amounts of ingested blood and serves as a major site of fluid absorption 12,87,88 (Supplementary Figure 4). CTSE is an intracellular protease that is highly expressed in gastrointestinal tissues, particularly in the stomach ${ }^{48,89}$. In the stomach, CTSE protein normally localizes to the canaliculi (invaginations) of parietal cells, which secrete hydrochloric acid, indicating that CTSE might be involved in secretory processes ${ }^{90}$. In D. rotundus, the canaliculi of parietal cells are specifically enriched in iron ${ }^{13}$, suggesting that their gastric parietal cells experienced a functional shift from hydrochloric acid secretion towards participating in iron excretion, which could have rendered CTSE dispensable. Consistent with this, CTSE has been reported lost in platypus ${ }^{91}$, which also lacks an acid-secreting stomach. However, CTSE is also lost in Cetartiodactyla that possess acid-secreting stomachs ${ }^{92}$ and, in addition to a possible role in gastric acid secretion, CTSE also has immune-related functions ${ }^{89}$. Thus, other CTSE functions could have also contributed to or represent the primary reason of CTSE loss in D. rotundus.

\section{Loss of ERN2 and low dietary fat content}

The loss of ERN2 (endoplasmic reticulum to nucleus signaling 2) in $D$. rotundus is likely a consequence of the low fat content of their blood diet. ERN2 is specifically expressed in gastrointestinal epithelia ${ }^{93}$ and encodes a transmembrane protein that inhibits the production of chylomicrons, which are lipoprotein particles that transport dietary lipids absorbed in enterocytes to other tissues ${ }^{94,95}$. Enterocytes of ERN2 
knockout mice were shown to secrete more chylomicrons, resulting in increased lipid absorption and a more pronounced hyperlipidemia on high-fat diets ${ }^{94,95}$. Interestingly, on a standard diet, ERN2 knockout mice did not exhibit hyperlipidemia, indicating that ERN2 limits intestinal lipid absorption only under conditions where excessive fat is available. Since blood has a very low fat content ${ }^{11}$, it is conceivable that regulatory mechanisms, which normally limit lipid absorption, became dispensable during vampire bat evolution, resulting in loss of ERN2.

\section{Loss of the pancreatic chymotrypsin CTRL}

Pancreatic proteases such as chymotrypsinogens and trypsinogens are among the most essential digestive enzymes ${ }^{96}$. They are produced by acinar cells of the exocrine pancreas and are secreted as inactive zymogens which, upon activation in the small intestine, digest proteins ${ }^{96}$. CTRL (chymotrypsin like) encodes one of four chymotrypsinogen isozymes and is considered a predictive biomarker for human pancreatic cancer ${ }^{97}$. In mice, CTRL represents a minor chymotrypsin isoform, constituting $\sim 10 \%$ of the chymotrypsinogen pool ${ }^{98}$. In vitro experiments showed that CTRL cleaves trypsinogens and thus inhibits the activation of protein-digesting trypsin ${ }^{98}$. Consistently, CTRL knockout in mice leads to a reduced activation of chymotrypsins and a slightly higher trypsin activity ${ }^{98}$, which could be relevant for the unique, protein-rich diet of vampire bats. Interestingly, recent evidence also indicates that acinar proteases including CTRL contribute to proliferation of beta cells ${ }^{99}$, providing another possible explanation for the loss of this gene in a bat species that exhibits a reduced beta cell mass ${ }^{16}$.

\section{Loss of CYP39A1 and advanced social behavior}

The loss of CYP39A1 (cytochrome P450 family 39 subfamily A member 1) could have contributed to the evolution of vampire bat's exceptional social behaviors and cognitive abilities ${ }^{20,100,101}$. CYP39A1 encodes an oxysterol 7- $\alpha$-hydroxylase enzyme ${ }^{102}$. Apart from a minor contribution to hepatic bile acid synthesis (Supplementary Figure 5), CYP39A1 is the only enzyme expressed in the brain that can degrade the cholesterol metabolite 24S-hydroxycholesterol ${ }^{103-106}$. 24S-hydroxycholesterol is an intermediate by-product during cholesterol elimination from the brain ${ }^{107}$. Unlike cholesterol, 24S-hydroxycholesterol can pass the blood-brain barrier. Therefore, the loss of the 24S-hydroxycholesterol-degrading CYP39A1 is expected to result in elevated systemic levels of this metabolite, which was observed in humans with CYP39A1 loss-offunction alleles ${ }^{108}$.

Since 24S-hydroxycholesterol also plays important neurophysiological roles, we hypothesize that CYP39A1 loss may be connected to the exceptional cognitive and social capabilities of D. rotundus. 24Shydroxycholesterol is a potent allosteric activator of $N$-methyl-D-aspartate receptors (NMDAR), which are glutamate-gated ion channels that mediate synaptic plasticity and memory formation ${ }^{109,110}$. Consistent with a positive effect of 24S-hydroxycholesterol on NMDAR activity and cognitive function, increased cerebral 24S-hydroxycholesterol levels improve spatial memory function in mice ${ }^{111,112}$, whereas reduced levels cause impaired learning and memory function ${ }^{113,114}$. NMDAR activity also exerts a strong influence on social behavior, as NMDAR agonists improve social behavior in rodents, whereas antagonists impair it ${ }^{115}$.

Intriguingly, vampire bats, the only lineage in our dataset that lost the 24S-hydroxycholesterol-metabolizing CYP39A1 gene, are distinguished from other bats by their exceptional social behavior and cognitive abilities. They reciprocally share regurgitated blood with roost mates that failed to obtain a nightly meal and 
would otherwise face starvation ${ }^{19}$. The decision with whom to share blood is primarily driven by recognizing contact calls of individuals that provided past blood donations, which demonstrates exceptional long term social memory ${ }^{20,100}$. Furthermore, non-kin adoption of orphaned offspring occurs in vampire bat colonies 101. Vampire bats also form long-lasting social bonds, evident by observations that individuals who cooperated in captivity retain their social network when released into the wild ${ }^{116}$. Vampire bats, as perhaps the most socially-advanced bats, were also found to have the largest relative neocortical volume among 276 measured bat species ${ }^{117}$. Interestingly, the 24S-hydroxycholesterol-interacting subunit of NMDAR (GLUN2B) is highly expressed at birth and plays an important role in cortical development ${ }^{110,118}$, raising the possibility that CYP39A1 loss may also be connected to the large neocortical volume of $D$. rotundus.

\section{Loss of cone phototransduction genes suggests rod monochromacy}

Our strict genomic screen revealed that $P D E 6 H$ is exclusively lost in vampire bats. PDE6H encodes the $Y^{\prime}-$ subunit of the cone phosphodiesterase, a component of the phototransduction cascade in cone cells ${ }^{119}$. Loss of function mutations in PDE6H cause total color blindness in humans ${ }^{119}$, but not in mice, where the rod phosphodiesterase isoform PDE6G compensates for PDE6H loss ${ }^{120}$. Given this cross-species variability, we investigated additional genes required for phototransduction in rods and cones in the 26 focal bat species. For rods, we found no phototransduction component (RHO, GNAT1, GNB1, GNGT1, PDE6A, $P D E 6 B, P D E 6 G)$ to be lost. Among the genes required for cone phototransduction (OPN1SW, OPN1LW, GNAT2, GNB3, GNGT2, PDE6C), we confirmed previously-reported losses of the short-wavelength sensitive opsin (OPN1SW) in the vampire bat and six other bats ${ }^{121-124}$ (Supplementary Figure 6). In addition, our analysis detected that $P D E 6 C$ is lost in the vampire and four other bats (Supplementary Figures 6,7$)$. Inactivating mutations in PDE6C in both humans and mice abolish cone function entirely, resulting in rod monochromacy, a condition where only rod photoreceptors remain functional ${ }^{125,126}$.

While ancestral Chiroptera were inferred to have two types of cones and dichromatic vision, many bats, including $D$. rotundus, lack cones that express a functional short-wavelength sensitive opsin (OPN1SW) 121-124. Whereas the lack of a functional OPN1SW alone suggested color blindness but maintenance of functional cones expressing the conserved OPN1LW (long wave sensitive opsin) gene, our discovery of repeated PDE6C losses suggests that $D$. rotundus and four other nocturnal Noctilionoidea may be functional rod monochromats. This condition, where all cone-based photoreception is abolished even if vestigial cone cells can still be detected, has been suggested for only a few other mammalian lineages so far $^{127}$. In light of their ecology, rod monochromacy is plausible in vampire bats, which lost both PDE6C and $P D E 6 H$. These strictly nocturnal bats are most active during the darkest periods of the night and even avoid moonshine ${ }^{128}$. Furthermore, to locate their prey, vampire bats have evolved non-visual sensory adaptations such as highly specialized auditory adaptations ${ }^{129}$, and an infrared sensing capability, which is unique among mammals ${ }^{6}$.

\section{Loss of the immune-related RNASE7 and a different pathogen profile of blood}

Feeding exclusively on blood, the immune system of vampire bats is regularly challenged with blood-borne pathogens ${ }^{130}$. However, because blood exhibits a low bacterial abundance but different species composition ${ }^{131,132}$, their intestinal tract is likely exposed to a different diversity of pathogens. We discovered that the immune-related RNASE7 (ribonuclease A family member 7) gene is lost in $D$. rotundus and intact in all other analyzed bats. 
RNASE7 encodes a secreted ribonuclease that has potent antimicrobial activity against various microorganisms ${ }^{133}$. In humans, RNASE7 is highly expressed in most epithelia including skin, urothelium and respiratory tract epithelium ${ }^{48,133}$. The gene is significantly downregulated in the skin and urinary tract of diabetic patients (potentially because RNASE7 expression can be induced by insulin signaling), which reduces innate immune defense capacities and likely contributes to the much higher incidence of bacterial skin and urinary tract infections in diabetic patients ${ }^{134,135}$. The exclusive loss of RNASE7 in vampire bats, which might also be related to their reduced insulin secretory capacities, predicts that vampire bats have a reduced capacity for secreting bactericidal peptides. While a previous study found that RNASE7 evolved under positive selection in vampire bats, which was interpreted as an adaptation towards increased exposition to blood-borne pathogens ${ }^{21}$, our analysis shows that RNASE7 is clearly inactivated, raises the possibility that its loss may be a consequence of exposure to a different pathogen diversity.

\section{Discussion}

Here, we used long read (HiFi) sequencing to generate a haplotype-resolved genome assembly of high completeness, contiguity and base accuracy for the common vampire bat Desmodus rotundus. Adding to previous studies ${ }^{34,136}$, our side-by-side comparison of gene content and inactivating mutations demonstrates that the HiFi assembly not only improves gene completeness but also base accuracy. A haplotype-resolved assembly also facilitates discriminating between homozygous and heterozygous (inactivating) mutations, which is more difficult in collapsed diploid assemblies. Using this new $D$. rotundus assembly and existing genomes of 25 other bats, we performed a genome-wide screen for genes that are specifically lost in the vampire bat lineage. This screen revealed 10 previously-unknown gene losses that are likely associated with derived phenotypic features of vampire bats, such as reduced insulin secretion (FFAR1, SLC30A8) and glycogen synthesis (PPP1R3E), a distinct gastric physiology (CTSE), and exceptional social behavior and cognitive abilities (CYP39A1). The loss of other genes (ERN2, CTRL, $R E P 15)$ is likely related to the biased nutrient composition of blood, which features low fat, high protein and high iron contents. Consistent with an association to vampire bat-specific changes in metabolism and digestion, many of these genes are highly expressed in relevant organ systems such as the pancreas (FFAR1, SLC30A8, CTRL) and gastrointestinal tissues (REP15, CTSE, ERN2). Finally, gene loss can also indicate previously-unknown phenotypes, exemplified here by the loss of $P D E 6 H$ and PDE6C, which suggest the complete lack of cone photoreceptor function (functional rod monochromacy). Similarly, the loss of RNASE7 may indicate differences in the immune system between $D$. rotundus and other bats, which deserves further studies. In particular, while bats are generally known for tolerating a larger diversity of viral and other pathogens, it is conceivable that their specialized diet exposes $D$. rotundus to a distinct pathogen profile, largely constrained to blood-borne pathogens. This hypothesis could be tested using metagenomics or related technologies to systematically characterize and compare pathogen profiles of vampire and other bats, ideally in matched environments.

Our finding that vampire bats, which naturally exhibit a reduced capacity for insulin secretion ${ }^{16}$, have lost FFAR1, a beta cell receptor that stimulates insulin secretion, provides an interesting contrast to fruit eating bats of the phyllostomid and pteropodid families, which exhibit an increased capacity for insulin secretion. 
These fruit bats have convergently adapted to sugar-rich diets ${ }^{137,138}$ and have convergently lost FFAR3 ${ }^{23,26}$, a different beta cell receptor that inhibits insulin secretion ${ }^{139}$. This suggests that losses of two different genes with opposite effects on insulin secretion are involved in opposite phenotypes in bats.

Which genes are lost during the course of evolution is influenced by several factors. One important factor underlying gene loss, including those identified here, is the absence of selection to preserve the function of certain genes as a consequence of adaptation to a new environment or different lifestyle. However, despite dispensability of gene function, several other factors constrain which genes are permitted to be lost in evolution ${ }^{25}$. For example, genes lost in mammals are generally depleted in essential functions and tend to have a lower degree of pleiotropy ${ }^{92}$. Indeed, the few known examples of pleiotropic gene losses in mammals refer to cases where most or all functions of the gene became dispensable (e.g. KLK8, INSL5, RXFP4, SLC4A9 ${ }^{28,29,140}$ ) or where additional gene functions are compensated by functionally related proteins (e.g. ACOX2, SLC27A5 ${ }^{141}$ ). Consistent with pleiotropy being a key restricting factor, the gene loss cases detected here largely refer to genes with specific functions and a low or no degree of pleiotropy. In addition to pleiotropy and essentiality, restricted expression patterns appear to be another factor permitting gene loss. For example, while the inactivated gene ERN2 exhibits a specific expression in the gastrointestinal tract, the ubiquitously expressed and functionally similar $E R N 1$ gene ${ }^{93}$ is intact in the vampire bat genome. Similarly, REP15, SLC30A8, CTSE, and CTRL have tissue-restricted expression patterns.

While dispensability of gene function is certainly the main explanation for gene losses in the vampire bat lineage, loss of ancestral genes can sometimes be beneficial in evolution and contribute to adaptations $25,26,28,29,142$. For example, the loss of REP15 could have contributed to enhanced iron elimination through shedding of iron-containing gastrointestinal cells, which likely represents an adaptation of vampire bats to their iron-rich blood diet. Another example is CYP39A1, whose loss is expected to result in elevated systemic levels of $24 \mathrm{~S}$-hydroxycholesterol. Since elevated levels of this cholesterol metabolite can positively affect cognitive function in animal models ${ }^{111,112}$, it is conceivable that loss of CYP39A1 in the vampire bat lineage may have contributed to their exceptional social behavior and cognitive abilities, which is a unique feature among bats.

In summary, our study provides novel insights into the genomic changes related to adaptations to sanguivory and the evolutionary importance of gene losses in general. Notably, a comprehensive understanding of how sanguivory, as a unique dietary specialization, has evolved, requires not only highquality genomic resources but also data on the organismal biology of vampire bats. Our study reveals gaps in our knowledge of vampire bat physiology, metabolism and immunity, highlighting the need to better characterize the phenotypic side of adaptations to their unique diet. 


\section{Methods}

\section{Sample collection for sequencing}

A D. rotundus male individual (ROMM126221) was collected in a mist net at Sabajo, Para, Suriname on 26 September 2017 as part of a larger environmental baseline study and euthanized with an overdose of isoflurane. The research permit was approved on 8 June 2017 by the Nature Conservation Division, Suriname Forest Service. Animal Use Protocol \#2017-19 was approved by the Animal Care Committee of the Royal Ontario Museum. The use of wild mammals in research followed the guidelines of the American Society of Mammalogists ${ }^{143}$.

\section{DNA extraction, library preparation and whole genome sequencing}

Sampled tissues were snap-frozen in liquid nitrogen immediately after dissection and stored at $-80^{\circ} \mathrm{C}$ until further processed. Mixed tissue of heart, liver, and spleen $(23 \mathrm{mg})$ was used for high molecular weight DNA extraction using the Nanobind Tissue Big DNA Kit (Circulomics, MD) according to the manufacturer's instructions. Final DNA purity and concentrations were measured using NanoPhotometer ${ }^{\circledR}$ (Implen $\mathrm{GmbH}$, Munich, Germany) and Qubit Fluorometer (Thermo Fisher Scientific, Waltham, MA). Two SMRTbell libraries were constructed following the instructions of the SMRTbell Express Prep kit v2.0 (Pacific Biosciences, Menlo Park, CA). The total input DNA for each library was approximately $5 \mu \mathrm{g}$. The libraries were loaded at an on-plate concentration of $80 \mathrm{pM}$ using diffusion loading. Four SMRT cell sequencing runs were performed on the Sequel System Ile in CCS mode using 30 hour movie time with 2 hours preextension and sequencing chemistry V2.0. The Dovetail Omni-C library was prepared from mixed tissue (heart, liver, and spleen) using the Dovetail тм Omni-C ${ }^{\text {тм }}$ kit (Dovetail Genomics, Scotts Valley, CA, USA) following the manufacturer's protocol (manual version 1.2 for mammalian samples). The Omni-C library was sequenced on a NovaSeq 6000 platform at Novogene (UK), generating 400 million $2 \times 150$ bp pairedend reads totaling $120 \mathrm{Gbp}$. The fragment size distribution and concentration of the final PacBio and Dovetail Omni-C library were assessed using a TapeStation (Agilent Technologies) and a Qubit Fluorometer (Thermo Fisher Scientific, Waltham, MA), respectively.

\section{D. rotundus genome assembly}

We called CCS reads ( $\mathrm{rq}>0.99$ ) from the subreads.bam file using PacBio ccs (version 6.0.0, https://github.com/PacificBiosciences/ccs). We then created the two contig assemblies using hifiasm (version 0.15.1-r331) ${ }^{144}$ with arguments -12 --h1 --h2 using the ccs reads and the HiC reads as input. This resulted in one contig assembly for each of the haplotypes in this species, which both went independently into the following scaffolding, gap-closing and polishing steps.

For scaffolding, we used SALSA2 (git commit 1b76bf63efb973583647a1eb95863d33ee6e09ad) ${ }^{145}$ and the Dovetail Omni-C mapping pipeline (https://omni-c.readthedocs.io/en/latest/fasta to bam.html). Briefly, we mapped HiC reads using BWA-MEM (version 0.7.17-r1188) ${ }^{146}$. Alignments were filtered using pairtools (version 0.3.0) with arguments parse --min-mapq 40 --walks-policy 5unique --max-inter-align-gap 30 to retain those alignments with high mapping quality, the most 5' alignments for conflicts and alignments without large gaps. We removed potential PCR duplicates using pairtools dedup. The resulting read-sorted bed file was used as input for SALSA2. We then performed a number of manual curation rounds to correct scaffolding errors and to scaffold those contigs which were not automatically scaffolded. To this end, we 
used cooler (version 0.8.11, https://github.com/open2c/cooler) and HiGlass ${ }^{147}$ to visually inspect the HiC maps and re-scaffolded the assembly using SeqKit (version 0.13.2) to re-arrange contigs and scaffolds into chromosome-level scaffolds.

After scaffolding, we closed additional assembly gaps using the lower-quality PacBio CLR read data that did not yield a CCS read. To this end, we mapped the original subreads.bam files to the scaffolded assembly using pbmm2 (version 1.3.0) with arguments --preset SUBREAD -N 1. Based on the read-piles created by reads spanning across gap regions, we computed consensus sequences for the gap regions and their $2 \mathrm{~kb}$ up/downstream flanks using gcpp (version 2.0.2-2.0.2). We filtered for high-confidence consensus sequences by requiring that no N's and no lower-case (acgt) characters remain in the consensus sequence. We then replaced the assembly gap and flanking region with high-confidence consensus sequences.

Despite the high accuracy of PacBio CCS reads, an assembly can still contain base errors due to errors in the consensus sequence calculation. In addition, lower base accuracy likely exists in the closed gap regions. To improve base accuracy, we polished both haplotype assemblies using all CCS reads. We tested both freebayes (version 1.3.2, https://github.com/freebayes/freebayes) and DeepVariant (version 1.1.0) ${ }^{148}$. Based on numbers of genes with inactivating mutations (computed by TOGA, see below) and the QV values computed by Merqury (version 1.0) ${ }^{32}$, DeepVariant vastly outperformed freebayes in correcting base errors. Therefore, for the final polishing round, we mapped all CCS reads to the scaffolded, gap-closed assemblies using pbmm2 with arguments: --preset CCS - $\mathrm{N} 1$ and called variants using DeepVariant. We then filtered for sites with 'genotype $1 / 1$ ' to specify that all or nearly all reads support an alternative sequence at this position and a 'PASS' filter value to specify that the site passed DeepVariant's internal filters. We then corrected base errors using bcftools consensus (version 1.12). Importantly, this procedure does not 'correct' any heterozygous or polymorphic regions but only those that are incorrect and not supported by any CCS reads.

\section{Repeat masking}

We used RepeatModeler (http://www.repeatmasker.org/, parameter -engine ncbi) to generate a de novo repeat library for the new $D$. rotundus genome assembly and used the resulting library with RepeatMasker (version 4.0.9, parameters -engine crossmatch -s) to soft-mask the genome.

\section{Genome alignments}

We used the human hg38 genome assembly as the reference and considered $D$. rotundus and 25 other bats as query species (Supplementary Table 1). To generate pairwise genome alignment chains as input for TOGA ${ }^{33}$, we first used LASTZ (version 1.04.03) ${ }^{149}$ with parameters $(K=2400, L=3000, Y=9400, H$ $=2000$ and the lastz default scoring matrix). These parameters are sensitive enough to capture orthologous exons between placental mammals ${ }^{150}$. Then, we used axtChain ${ }^{151}$ (default parameters except linearGap=loose) to compute co-linear alignment chains, RepeatFiller ${ }^{152}$ (default parameters) to capture previously-missed alignments between repetitive regions and chainCleaner ${ }^{153}$ (default parameters except minBrokenChainScore $=75000$ and -doPairs) to improve alignment specificity. 


\section{Using TOGA to infer orthologous genes and detect gene losses}

To compare gene completeness and to screen for gene losses, we used TOGA ${ }^{33}$, a method that uses pairwise genome alignment chains between an annotated reference genome (here human hg38 assembly) and other query species. Briefly, TOGA uses machine learning to infer orthologous loci for each reference transcript, utilizing that orthologous genes display more alignments between intronic and flanking intergenic regions ${ }^{33}$. TOGA then projects each reference transcript to its orthologous query locus using CESAR 2.0 ${ }^{154}$, a Hidden Markov model method that takes reading frame and splice site annotation of the reference exons into account. CESAR avoids spurious frameshifts, is able to detect evolutionary splice site shifts and precise intron deletions ${ }^{154,155}$. Using the CESAR alignment, TOGA determines whether the transcript has inactivating mutations (frameshifting mutations, premature stop codons, splice site disrupting mutations, deletions of entire coding exons). TOGA also uses orthologous alignment chains to detect genes that are entirely deleted in the query assembly and distinguishes real exon or gene deletions from missing sequence caused by assembly gaps.

TOGA classifies each transcript into one of five categories. Classification 'intact', 'partially intact' and 'missing' refers to transcripts that lack inactivating mutations in the middle $80 \%$ of the coding region. TOGA specifically considers this central part of the coding region, since truly conserved genes can have inactivating mutations in the first or last $10 \%$ of the coding region (near the $\mathrm{N}$ - or C-terminus) ${ }^{33,155}$. For intact transcripts, the central part of the coding region is completely present in the assembly, whereas for partially intact ( $\geq 50 \%$ present) and missing ( $<50 \%$ present) transcripts some coding parts are missing due to assembly gaps or fragmentation. Classification 'lost' refers to transcripts that have at least two inactivating mutations in at least two exons. All other transcripts, having a single inactivating mutation or mutations in only a single exon, are classified as 'uncertain loss', reflecting the possibility that only an exon but not the entire gene could be lost.

Considering all input transcripts of a gene, TOGA uses the precedence order 'intact', 'partially intact', 'uncertain loss', 'lost', 'missing' to provide a gene classification. That means, TOGA only classifies a gene as lost if all its transcripts are classified as lost (at all orthologous loci if there is more than one).

\section{Gene completeness among bat genomes}

To compare gene completeness between assemblies, we first obtained a set of genes that likely already existed in the placental mammal ancestor. To this end, we used the human GENCODE V38 (Ensembl 104) gene annotation ${ }^{156}$ as input and applied TOGA to the genomes of 11 afrotherian (represented by aardvark, cape golden mole, small Madagascar hedgehog, Talazac's shrew tenrec, cape elephant shrew, dugong, manatee, Asiatic elephant, African savanna elephant, cape rock hyrax, yellow-spotted hyrax) and five xenarthran (represented by southern two-toed sloth, Hoffmann's two-fingered sloth, nine-banded armadillo, giant anteater, southern tamandua) mammals. Since each input gene is by definition present in human (superorder Boreoeutheria), we considered a gene as ancestral if it is also conserved in the other two basal placental superorders Afrotheria and Xenarthra. Specifically, we selected genes that are classified by TOGA as intact or partially intact in at least one afrotherian and at least one xenarthran genome. Note that this requirement assures placental mammal ancestry irrespective of the exact basal split of placental mammals, which is difficult to resolve ${ }^{157}$. This procedure resulted in a set of 18,430 genes. 
Next, we applied TOGA to D. rotundus and the 25 other bat genomes (Supplementary Table 1). Considering the 18,430 ancestral genes, we counted per species how many gene have an intact reading frame (TOGA classification 'intact'), have inactivating mutations (TOGA classifications 'loss' and 'uncertain loss') or have missing sequence (TOGA classifications 'partially intact' and 'missing'). This breakdown is shown in Figure 1C.

\section{Screen for gene losses}

To identify gene losses that among bats occurred specifically in the vampire bat lineage, we used the above-generated TOGA data for the 26 bats. We first filtered for genes that have at least one inactivating mutation in the middle $80 \%$ of the coding sequence (TOGA classification 'lost' or 'uncertain loss') in both D. rotundus haplotype assemblies.

Base errors can also occur in other bat assemblies, which may result in missing real vampire bat-specific gene losses (false negatives). To reduce the false negative rate, we conducted the initial screen with less strict requirements and allowed per gene up to three non-vampire bat species to be classified as 'missing', 'partially missing' or 'uncertain loss', resulting in 52 candidate genes. Then, to assess which of these candidate genes are a true vampire specific gene losses, we mapped available Illumina reads of the same species to each included genome assembly using BWA-MEM (version 0.7.7-r441) ${ }^{146}$ and removed duplicates with Picard (version 2.21.4) (http://broadinstitute.github.io/picard) (SRA identifiers are listed in Supplementary Table 4) and examined whether putative inactivating mutations are supported by raw reads and if they are heterozygous or homozygous. We excluded all genes as non-vampire specific losses that have homozygous mutations in at least one other bat species and furthermore required that not more than $60 \%$ of the coding sequence remains functional in D. rotundus. We kept SLC30A8, which has a heterozygous stop codon in exon 4 in Micronycteris hirsuta. We excluded genes belonging to the large and fast-evolving olfactory receptor family. This procedure revealed the 13 vampire specific gene losses that are discussed in the main text.

Finally, to confirm the correctness of all 10 previously-unknown vampire bat-specific gene losses, we manually inspected the pairwise alignment chains in the UCSC genome browser ${ }^{158}$, which showed that the remnants of all 10 genes are located in a conserved gene order (synteny) context. Inspecting chiropteran pairwise alignment chains also showed that none of the 10 genes exhibit duplications in $D$. rotundus or other bats, which excludes the possibility that a functional gene copy remained in $D$. rotundus. Finally, we further verified the correctness of the inactivating mutations by requiring that the gene is also classified as 'lost' or 'uncertain loss' in the Illumina $D$. rotundus assembly with at least one shared homozygous (based on aligned Illumina sequencing reads) inactivating mutation, thus providing base support from two sequencing technologies.

\section{Relaxed selection}

To test the 10 genes for relaxation of selection, we obtained pairwise codon alignments between human and each query bat from TOGA. Codons affected by frameshifting insertions or deletions and premature stop codons were replaced by 'NNN' codons to maintain a reading frame. A multiple codon alignment was produced with MACSE v2 ${ }^{159}$ and cleaned with HmmCleaner ${ }^{160}$ with default cost values. The resulting 
alignments were used to investigate whether the gene evolves under relaxed selection with RELAX ${ }^{45}$, specifying the $D$. rotundus branch as the foreground and all other branches as background.

\section{Gene expression}

We investigated RNA expression of the 10 target gene losses using available transcriptome sequencing data for $D$. rotundus from 11 tissues (heart, stomach, intestine, liver, gallbladder, pancreas, spleen, kidney, olfactory epithelium, eye and tongue). The paired-end sequencing read sets were downloaded from NCBI (accessions listed in Supplementary Table 5) and mapped to the new D. rotundus haplotype 1 assembly using STAR (version 2.7.3) ${ }^{161}$. Target loci were then manually examined in IGV ${ }^{162 .}$

\section{Whole blood iron measurements}

All animal captures were approved by the National Environmental Office (License number 77322-1, Sisbio, Brazil) and all experiments were approved by the Ethics Committee from Federal University of Viçosa (License number 10/2021, CEUA/UFV, Brazil). Nine D. rotundus, sixteen Artibeus lituratus and four Myotis myotis individuals were captured with mist nets in Viçosa, Minas Gerais, Brazil and euthanized through cervical dislocation followed by decapitation. All blood samples (100 - $400 \mu \mathrm{l}$ ) were dried using a stove and mineralized in a nitric-perchloric acid solution (1.5 mL total volume) until organic matter was removed. The final extract was used to determine iron concentrations through atomic absorption spectrophotometry (Shimadzu AA-6701F). Whole blood iron levels were compared between species with a two-sided t-test.

\section{Data availability}

The haplotype-resolved $D$. rotundus assembly and the TOGA annotations are freely available at https://bds.mpi-cbg.de/hillerlab/VampireBatGenome/. The sequencing data and genome assembly is also uploaded to NCBI.

\section{Competing interests}

The authors have no competing interests.

\section{Acknowledgments}

We would like to thank the UCSC genome browser group for providing software and genome annotations, and the Computer Service Facilities of the MPI-CBG and MPI-PKS for their support. We also thank the Genome Technology Center (RGTC) at Radboudumc for the use of the Sequencing Core Facility (Nijmegen, The Netherlands). Furthermore, we want to thank Robert Cornman for support concerning the Aeorestes cinereus assembly, and David Lagman and Dan Larhammar for helpful feedback on the phototransduction cascade. Figures 3C, 4 and S3A created with Biorender (https://biorender.com). This work was supported by the Max Planck Society, the National Council for Scientific and Technological Development (CNPq, Brazil), funding from Environmental Services \& Support (ESS) for fieldwork in Suriname, and the LOEWE-Centre for Translational Biodiversity Genomics (TBG) funded by the Hessen State Ministry of Higher Education, Research and the Arts (HMWK). 


\section{References}

1

2

3

4

5

6

Baker, R. J., Bininda-Emonds, O. R. P., Mantilla-Meluk, H., Porter, C. A. \& Van Den Bussche, R. A. in Evolutionary History of Bats: Fossils, Molecules and Morphology Cambridge Studies in Morphology and Molecules: New Paradigms in Evolutionary Bio (eds Gregg F. Gunnell \& Nancy B. Simmons) 385-409 (Cambridge University Press, 2012).

Wilkinson, G. S. Vampire bats. Current biology : CB 29, R1216-R1217, doi:10.1016/j.cub.2019.10.052 (2019). Schmidt, U. Natural history of vampire bats. (CRC Press, 2018).

Schmidt, U. Olfactory threshold and odour discrimination of the vampire bat. (Desmodus rotundus). Period Biol 75, 89-92 (1973).

Heffner, R. S., Koay, G. \& Heffner, H. E. Hearing in American leaf-nosed bats. IV: the Common vampire bat, Desmodus rotundus. Hear Res 296, 42-50, doi:10.1016/j.heares.2012.09.011 (2013).

Gracheva, E. O. et al. Ganglion-specific splicing of TRPV1 underlies infrared sensation in vampire bats. Nature 476, 88-91, doi:10.1038/nature10245 (2011).

Riskin, D. K., Parsons, S., Schutt, W. A., Jr., Carter, G. G. \& Hermanson, J. W. Terrestrial locomotion of the New Zealand short-tailed bat Mystacina tuberculata and the common vampire bat Desmodus rotundus. The Journal of experimental biology 209, 1725-1736, doi:10.1242/jeb.02186 (2006).

Davis, J. S., Nicolay, C. W. \& Williams, S. H. A comparative study of incisor procumbency and mandibular morphology in vampire bats. J Morphol 271, 853-862, doi:10.1002/jmor.10840 (2010).

Low, D. H. et al. Dracula's children: molecular evolution of vampire bat venom. J Proteomics 89, 95-111, doi:10.1016/j.jprot.2013.05.034 (2013).

McNab, B. K. Energetics and the Distribution of Vampires. Journal of Mammalogy 54, 131-144, doi:10.2307/1378876 (1973).

Breidenstein, C. P. Digestion and Assimilation of Bovine Blood by a Vampire Bat (Desmodus rotundus). Journal of Mammalogy 63, 482-484, doi:10.2307/1380446 (1982).

Rouk, C. S. \& Glass, B. P. Comparative gastric histology of five North and Central American bats. J Mammal 51, 455-490 (1970).

Morton, D. \& Wimsatt, W. A. Distribution of iron in the gastrointestinal tract of the common vampire bat: evidence for macrophage-linked iron clearance. The Anatomical record 198, 183-192, doi:10.1002/ar.1091980206 (1980).

Graca-Souza, A. V. et al. Adaptations against heme toxicity in blood-feeding arthropods. Insect Biochem Mol Biol 36, 322-335, doi:10.1016/j.ibmb.2006.01.009 (2006).

Muckenthaler, M. U., Rivella, S., Hentze, M. W. \& Galy, B. A Red Carpet for Iron Metabolism. Cell 168, 344-361, doi:10.1016/j.cell.2016.12.034 (2017).

Freitas, M. B. et al. Reduced insulin secretion and glucose intolerance are involved in the fasting susceptibility of common vampire bats. General and comparative endocrinology 183, 1-6, doi:10.1016/j.ygcen.2012.11.023 (2013). Freitas, M. B., Welker, A. F., Millan, S. F. \& Pinheiro, E. C. Metabolic responses induced by fasting in the common vampire bat Desmodus rotundus. Journal of comparative physiology. B, Biochemical, systemic, and environmental physiology 173, 703-707, doi:10.1007/s00360-003-0383-3 (2003).

Freitas, M. B., Passos, C. B., Vasconcelos, R. B. \& Pinheiro, E. C. Effects of short-term fasting on energy reserves of vampire bats (Desmodus rotundus). Comparative biochemistry and physiology. Part B, Biochemistry \& molecular biology 140, 59-62, doi:10.1016/j.cbpc.2004.09.023 (2005).

Wilkinson, G. S. Reciprocal food sharing in the vampire bat. Nature 308, 181-184, doi:10.1038/308181a0 (1984). Carter, G. G. \& Wilkinson, G. S. Food sharing in vampire bats: reciprocal help predicts donations more than relatedness or harassment. Proceedings. Biological sciences / The Royal Society 280, 20122573, doi:10.1098/rspb.2012.2573 (2013).

Zepeda Mendoza, M. L. et al. Hologenomic adaptations underlying the evolution of sanguivory in the common vampire bat. Nat Ecol Evol 2, 659-668, doi:10.1038/s41559-018-0476-8 (2018).

2 Gutierrez-Guerrero, Y. T. et al. Genomic consequences of dietary diversification and parallel evolution due to nectarivory in leaf-nosed bats. Gigascience 9, doi:10.1093/gigascience/giaa059 (2020).

Wang, K. et al. Molecular adaptation and convergent evolution of frugivory in Old World and neotropical fruit bats. Mol Ecol, doi:10.1111/mec.15542 (2020).

Hong, W. \& Zhao, H. Vampire bats exhibit evolutionary reduction of bitter taste receptor genes common to other bats. Proceedings. Biological sciences / The Royal Society 281, 20141079, doi:10.1098/rspb.2014.1079 (2014). Albalat, R. \& Canestro, C. Evolution by gene loss. Nature reviews. Genetics 17, 379-391, doi:10.1038/nrg.2016.39 (2016).

Sharma, V. et al. A genomics approach reveals insights into the importance of gene losses for mammalian adaptations. Nature communications 9, 1215, doi:10.1038/s41467-018-03667-1 (2018).

Sharma, V., Lehmann, T., Stuckas, H., Funke, L. \& Hiller, M. Loss of RXFP2 and INSL3 genes in Afrotheria shows that testicular descent is the ancestral condition in placental mammals. PLoS Biol 16, e2005293, doi:10.1371/journal.pbio.2005293 (2018).

Hecker, N., Sharma, V. \& Hiller, M. Convergent gene losses illuminate metabolic and physiological changes in herbivores and carnivores. Proceedings of the National Academy of Sciences of the United States of America 116, 3036-3041, doi:10.1073/pnas.1818504116 (2019). 
Huelsmann, M. et al. Genes lost during the transition from land to water in cetaceans highlight genomic changes associated with aquatic adaptations. Sci Adv 5, eaaw6671, doi:10.1126/sciadv.aaw6671 (2019). of a human genome. Nat Biotechnol 37, 1155-1162, doi:10.1038/s41587-019-0217-9 (2019).

Santos, N., Fagundes, V., Yonenaga-Yassuda, Y. \& De Souza, M. J. Comparative karyology of Brazilian vampire bats Desmodus rotundus and Diphylla ecaudata (Phyllostomidae, Chiroptera): banding patterns, base-specific fluorochromes and FISH of ribosomal genes. Hereditas 134, 189-194, doi:10.1111/j.1601-5223.2001.00189.x (2001). assessment for genome assemblies. Genome Biol 21, 245, doi:10.1186/s13059-020-02134-9 (2020). Kirilenko, B. M. et al. TOGA: a machine-learning approach to integrate gene annotation with orthology inference at scale. (in prep.). Jebb, D. et al. Six reference-quality genomes reveal evolution of bat adaptations. Nature 583, 578-584, doi:10.1038/s41586-020-2486-3 (2020). Lindblad-Toh, K. et al. A high-resolution map of human evolutionary constraint using 29 mammals. Nature 478 , 476-482, doi:10.1038/nature10530 (2011).

Seim, I. et al. Genome analysis reveals insights into physiology and longevity of the Brandt's bat Myotis brandtii. Nature communications 4, 2212, doi:10.1038/ncomms3212 (2013).

Zhang, G. et al. Comparative analysis of bat genomes provides insight into the evolution of flight and immunity. Science 339, 456-460, doi:10.1126/science.1230835 (2013).

Eckalbar, W. L. et al. Transcriptomic and epigenomic characterization of the developing bat wing. Nat Genet $\mathbf{4 8}$, 528-536, doi:10.1038/ng.3537 (2016).

Dong, D. et al. The Genomes of Two Bat Species with Long Constant Frequency Echolocation Calls. Molecular biology and evolution 34, 20-34, doi:10.1093/molbev/msw231 (2017).

Pinzari, C. A. et al. Analysis of Genomic Sequence Data Reveals the Origin and Evolutionary Separation of Hawaiian Hoary Bat Populations. Genome Biol Evol 12, 1504-1514, doi:10.1093/gbe/evaa137 (2020). Zoonomia, C. A comparative genomics multitool for scientific discovery and conservation. Nature 587, 240-245, doi:10.1038/s41586-020-2876-6 (2020).

Datzmann, T., von Helversen, O. \& Mayer, F. Evolution of nectarivory in phyllostomid bats (Phyllostomidae Gray, 1825, Chiroptera: Mammalia). BMC Evol Biol 10, 165, doi:10.1186/1471-2148-10-165 (2010). Rojas, D., Warsi, O. M. \& Davalos, L. M. Bats (Chiroptera: Noctilionoidea) Challenge a Recent Origin of Extant Neotropical Diversity. Systematic biology 65, 432-448, doi:10.1093/sysbio/syw011 (2016). 2642-2650, doi:10.1093/molbev/msq152 (2010). Wertheim, J. O., Murrell, B., Smith, M. D., Kosakovsky Pond, S. L. \& Scheffler, K. RELAX: detecting relaxed selection in a phylogenetic framework. Molecular biology and evolution 32, 820-832, doi:10.1093/molbev/msu400 (2015). Strick, D. J. \& Elferink, L. A. Rab15 effector protein: a novel protein for receptor recycling from the endocytic recycling compartment. Mol Biol Cell 16, 5699-5709, doi:10.1091/mbc.e05-03-0204 (2005). Stasiak, I. M. et al. Iron storage disease (hemochromatosis) and hepcidin response to iron load in two species of pteropodid fruit bats relative to the common vampire bat. Journal of comparative physiology. B, Biochemical, systemic, and environmental physiology 188, 683-694, doi:10.1007/s00360-018-1155-4 (2018). Uhlen, M. et al. Towards a knowledge-based Human Protein Atlas. Nat Biotechnol 28, 1248-1250, doi:10.1038/nbt1210-1248 (2010).

Elferink, L. A. \& Strick, D. J. Functional properties of rab15 effector protein in endocytic recycling. Methods Enzymol 403, 732-743, doi:10.1016/S0076-6879(05)03064-8 (2005). Chen, E. et al. Alteration of tumor suppressor BMP5 in sporadic colorectal cancer: a genomic and transcriptomic profiling based study. Mol Cancer 17, 176, doi:10.1186/s12943-018-0925-7 (2018). Brookes, M. J. et al. Modulation of iron transport proteins in human colorectal carcinogenesis. Gut 55, 1449-1460, doi:10.1136/gut.2006.094060 (2006). Williams, J. M. et al. Epithelial cell shedding and barrier function: a matter of life and death at the small intestinal villus tip. Vet Pathol 52, 445-455, doi:10.1177/0300985814559404 (2015). Mercadante, C. J. et al. Gastrointestinal iron excretion and reversal of iron excess in a mouse model of inherited iron excess. Haematologica 104, 678-689, doi:10.3324/haematol.2018.198382 (2019). Neely, B. A. et al. Surveying the Vampire Bat (Desmodus rotundus) Serum Proteome: A Resource for Identifying Immunological Proteins and Detecting Pathogens. J Proteome Res 20, 2547-2559, doi:10.1021/acs.jproteome.0c00995 (2021). Mancini, A. D. \& Poitout, V. The fatty acid receptor FFA1/GPR40 a decade later: how much do we know? Trends Endocrinol Metab 24, 398-407, doi:10.1016/j.tem.2013.03.003 (2013). Latour, M. G. et al. GPR40 is necessary but not sufficient for fatty acid stimulation of insulin secretion in vivo. Diabetes 56, 1087-1094, doi:10.2337/db06-1532 (2007). piphasic insulin secretion and its amplification by Metab 316, E475-E486, doi:10.1152/ajpendo.00380.2018 (2019). Lan, H. et al. Lack of FFAR1/GPR40 does not protect mice from high-fat diet-induced metabolic disease. Diabetes 57, 2999-3006, doi:10.2337/db08-0596 (2008). 
Tomita, T. et al. Expression of the gene for a membrane-bound fatty acid receptor in the pancreas and islet cell tumours in humans: evidence for GPR40 expression in pancreatic beta cells and implications for insulin secretion. Diabetologia 49, 962-968, doi:10.1007/s00125-006-0193-8 (2006). Del Guerra, S. et al. G-protein-coupled receptor 40 (GPR40) expression and its regulation in human pancreatic islets: the role of type 2 diabetes and fatty acids. Nutr Metab Cardiovasc Dis 20, 22-25, doi:10.1016/j.numecd.2009.02.008 (2010).

Edfalk, S., Steneberg, P. \& Edlund, H. Gpr40 is expressed in enteroendocrine cells and mediates free fatty acid stimulation of incretin secretion. Diabetes 57, 2280-2287, doi:10.2337/db08-0307 (2008). Yamashima, T. Dual effects of the non-esterified fatty acid receptor 'GPR40' for human health. Prog Lipid Res 58, 40-50, doi:10.1016/j.plipres.2015.01.002 (2015). Nicolson, T. J. et al. Insulin storage and glucose homeostasis in mice null for the granule zinc transporter ZnT8 and studies of the type 2 diabetes-associated variants. Diabetes 58, 2070-2083, doi:10.2337/db09-0551 (2009). Pound, L. D. et al. The physiological effects of deleting the mouse SLC30A8 gene encoding zinc transporter-8 are influenced by gender and genetic background. PloS one 7, e40972, doi:10.1371/journal.pone.0040972 (2012). Chimienti, F., Devergnas, S., Favier, A. \& Seve, M. Identification and cloning of a beta-cell-specific zinc transporter, ZnT-8, localized into insulin secretory granules. Diabetes 53, 2330-2337, doi:10.2337/diabetes.53.9.2330 (2004). Dunn, M. F. Zinc-ligand interactions modulate assembly and stability of the insulin hexamer -- a review. Biometals 18, 295-303, doi:10.1007/s10534-005-3685-y (2005).

Burguera, M., Burguera, J. L. \& Alarcón, O. M. Flow injection and microwave-oven sample decomposition for determination of copper, zinc and iron in whole blood by atomic absorption spectrometry. Analytica Chimica Acta 179, 351-357, doi:https://doi.org/10.1016/S0003-2670(00)84479-7 (1986). EFSA Panel on Dietetic Products, N. \& Allergies. Scientific Opinion on Dietary Reference Values for zinc. EFSA Journal 12, 3844, doi:https://doi.org/10.2903/i.efsa.2014.3844 (2014).

Peres, J. M. et al. Improvement of zinc intestinal absorption and reduction of zinc/iron interaction using metal bound to the caseinophosphopeptide 1-25 of beta-casein. Reprod Nutr Dev 38, 465-472, doi:10.1051/rnd:19980410 (1998).

Kondaiah, P., Sharp, P. A. \& Pullakhandam, R. Zinc induces iron egress from intestinal Caco-2 cells via induction of Hephaestin: A role for PI3K in intestinal iron absorption. Biochemical and biophysical research communications 523, 987-992, doi:10.1016/j.bbrc.2020.01.023 (2020).

Pound, L. D. et al. Deletion of the mouse Slc30a8 gene encoding zinc transporter-8 results in impaired insulin secretion. The Biochemical journal 421, 371-376, doi:10.1042/BJ20090530 (2009). Bosma, K. J. et al. Evidence that Evolution of the Diabetes Susceptibility Gene SLC30A8 that Encodes the Zinc Transporter ZnT8 Drives Variations in Pancreatic Islet Zinc Content in Multiple Species. J Mol Evol 87, 147-151, doi:10.1007/s00239-019-09898-0 (2019).

Havu, N., Lundgren, G. \& Falkmer, S. Zinc and manganese contents of micro-dissected pancreatic islets of some rodents. A microchemical study in adult and newborn guinea pigs, rats, Chinese hamsters and spiny mice. Acta endocrinologica 86, 570-577 (1977). pancreas of the sheep (ovis aries)]. Ann Histochim 16, 91-99 (1971).

Petkov, P. E., Gospodinov, C. \& Galabova, R. Histochemistry of Langerhans' islets in the pancreas of cattle (Bos Taurus L.). Histochemie 23, 127-137, doi:10.1007/BF00305846 (1970).

Zalewski, P. D. et al. Video image analysis of labile zinc in viable pancreatic islet cells using a specific fluorescent probe for zinc. J Histochem Cytochem 42, 877-884, doi:10.1177/42.7.8014471 (1994). Hunt, J. R. Bioavailability of iron, zinc, and other trace minerals from vegetarian diets. Am J Clin Nutr 78, 633S639S, doi:10.1093/ajcn/78.3.633S (2003). Semrad, C. E. Zinc and intestinal function. Curr Gastroenterol Rep 1, 398-403, doi:10.1007/s11894-999-0021-7 (1999).

Munro, S., Ceulemans, H., Bollen, M., Diplexcito, J. \& Cohen, P. T. A novel glycogen-targeting subunit of protein phosphatase 1 that is regulated by insulin and shows differential tissue distribution in humans and rodents. FEBS $J$ 272, 1478-1489, doi:10.1111/j.1742-4658.2005.04585.x (2005).

80 Roach, P. J. Glycogen and its metabolism. Curr Mol Med 2, 101-120, doi:10.2174/1566524024605761 (2002).

81 Petersen, M. C., Vatner, D. F. \& Shulman, G. I. Regulation of hepatic glucose metabolism in health and disease. Nat Rev Endocrinol 13, 572-587, doi:10.1038/nrendo.2017.80 (2017). Aschenbach, W. G. et al. The muscle-specific protein phosphatase PP1G/R(GL)(G(M))is essential for activation of glycogen synthase by exercise. J Biol Chem 276, 39959-39967, doi:10.1074/jbc.M105518200 (2001). Mehta, M. B. et al. Hepatic protein phosphatase 1 regulatory subunit 3B (Ppp1r3b) promotes hepatic glycogen synthesis and thereby regulates fasting energy homeostasis. J Biol Chem 292, 10444-10454, doi:10.1074/jbc.M116.766329 (2017).

Berman, H. K., O'Doherty, R. M., Anderson, P. \& Newgard, C. B. Overexpression of protein targeting to glycogen (PTG) in rat hepatocytes causes profound activation of glycogen synthesis independent of normal hormone- and substrate-mediated regulatory mechanisms. J Biol Chem 273, 26421-26425, doi:10.1074/jbc.273.41.26421 (1998). Crosson, S. M., Khan, A., Printen, J., Pessin, J. E. \& Saltiel, A. R. PTG gene deletion causes impaired glycogen synthesis and developmental insulin resistance. The Journal of clinical investigation 111, 1423-1432, doi:10.1172/JCl17975 (2003). 
bioRxiv preprint doi: https://doi.org/10.1101/2021.10.18.462363; this version posted October 19, 2021. The copyright holder for this preprint

(which was not certified by peer review) is the author/funder, who has granted bioRxiv a license to display the preprint in perpetuity. It is made available under aCC-BY-ND 4.0 International license.

Zhang, Y. et al. Ablation of PPP1R3G reduces glycogen deposition and mitigates high-fat diet induced obesity. Mol Cell Endocrinol 439, 133-140, doi:10.1016/j.mce.2016.10.036 (2017).

Park, H. \& Hall, E. R. The Gross Anatomy of the Tongues and Stomachs of Eight New World Bats. Transactions of the Kansas Academy of Science (1903-) 54, 64-72, doi:10.2307/3626255 (1951).

Wimsatt, W. A. \& Guerriere, A. Observations on the Feeding Capacities and Excretory Functions Of Captive Vampire Bats1. Journal of Mammalogy 43, 17-27, doi:10.2307/1376876 (1962).

Zaidi, N., Hermann, C., Herrmann, T. \& Kalbacher, H. Emerging functional roles of cathepsin E. Biochemical and biophysical research communications 377, 327-330, doi:10.1016/j.bbrc.2008.10.034 (2008).

Saku, T., Sakai, H., Shibata, Y., Kato, Y. \& Yamamoto, K. An immunocytochemical study on distinct intracellular localization of cathepsin $E$ and cathepsin D in human gastric cells and various rat cells. J Biochem 110, 956-964, doi:10.1093/oxfordjournals.jbchem.a123696 (1991).

Ordonez, G. R. et al. Loss of genes implicated in gastric function during platypus evolution. Genome Bio/ 9, R81, doi:10.1186/gb-2008-9-5-r81 (2008).

Sharma, V. \& Hiller, M. Losses of human disease-associated genes in placental mammals. NAR Genom Bioinform 2, lqz012, doi:10.1093/nargab/lqz012 (2020).

Bertolotti, A. et al. Increased sensitivity to dextran sodium sulfate colitis in IRE1beta-deficient mice. The Journal of clinical investigation 107, 585-593, doi:10.1172/JCI11476 (2001).

lqbal, J. et al. IRE1 beta inhibits chylomicron production by selectively degrading MTP mRNA. Cell Metab 7, 445455, doi:10.1016/j.cmet.2008.03.005 (2008).

lqbal, J. et al. Increased intestinal lipid absorption caused by Ire1beta deficiency contributes to hyperlipidemia and atherosclerosis in apolipoprotein E-deficient mice. Circulation research 110, 1575-1584,

doi:10.1161/CIRCRESAHA.112.264283 (2012).

Whitcomb, D. C. \& Lowe, M. E. Human pancreatic digestive enzymes. Dig Dis Sci 52, 1-17, doi:10.1007/s10620006-9589-z (2007).

Sun, D., Jin, H., Zhang, J. \& Tan, X. Integrated whole genome microarray analysis and immunohistochemical assay identifies COL11A1, GJB2 and CTRL as predictive biomarkers for pancreatic cancer. Cancer Cell Int 18, 174, doi:10.1186/s12935-018-0669-x (2018).

Mosztbacher, D., Jancso, Z. \& Sahin-Toth, M. Loss of chymotrypsin-like protease (CTRL) alters intrapancreatic protease activation but not pancreatitis severity in mice. Scientific reports 10, 11731, doi:10.1038/s41598-02068616-9 (2020).

Hostelley, T. L. et al. Exocrine pancreas proteases regulate beta-cell proliferation in zebrafish ciliopathy models and in murine systems. Biol Open 10, doi:10.1242/bio.046839 (2021).

Carter, G. G. \& Wilkinson, G. S. Common vampire bat contact calls attract past food-sharing partners. Animal Behaviour 116, 45-51, doi:10.1016/j.anbehav.2016.03.005 (2016).

Razik, I., Brown, B. K. G., Page, R. A. \& Carter, G. G. Non-kin adoption in the common vampire bat. $R$ Soc Open Sci 8, 201927, doi:10.1098/rsos.201927 (2021).

Li-Hawkins, J., Lund, E. G., Bronson, A. D. \& Russell, D. W. Expression cloning of an oxysterol 7alphahydroxylase selective for 24-hydroxycholesterol. J Biol Chem 275, 16543-16549, doi:10.1074/jbc.M001810200 (2000).

Grabovec, I. P. et al. Ligand-binding properties and catalytic activity of the purified human 24-hydroxycholesterol 7alpha-hydroxylase, CYP39A1. J Steroid Biochem Mol Biol 193, 105416, doi:10.1016/j.jsbmb.2019.105416 (2019). Norlin, M., Toll, A., Bjorkhem, I. \& Wikvall, K. 24-hydroxycholesterol is a substrate for hepatic cholesterol 7alphahydroxylase (CYP7A). J Lipid Res 41, 1629-1639 (2000).

Yantsevich, A. V. et al. Human steroid and oxysterol 7alpha-hydroxylase CYP7B1: substrate specificity, azole binding and misfolding of clinically relevant mutants. FEBS J 281, 1700-1713, doi:10.1111/febs.12733 (2014). Knabe, C., Sudhop, T., von Bergmann, K. \& Lutjohann, D. Degradation of 24S-hydroxycholesterol in men is not regulated by CYP7A1. Int J Clin Pharmacol Ther 45, 577-582, doi:10.5414/cpp45577 (2007).

Russell, D. W., Halford, R. W., Ramirez, D. M., Shah, R. \& Kotti, T. Cholesterol 24-hydroxylase: an enzyme of cholesterol turnover in the brain. Annual review of biochemistry 78, 1017-1040,

doi:10.1146/annurev.biochem.78.072407.103859 (2009).

Stiles, A. R. et al. Genetic, anatomic, and clinical determinants of human serum sterol and vitamin D levels. Proceedings of the National Academy of Sciences of the United States of America 111, E4006-4014, doi:10.1073/pnas.1413561111 (2014).

Paul, S. M. et al. The major brain cholesterol metabolite 24(S)-hydroxycholesterol is a potent allosteric modulator of N-methyl-D-aspartate receptors. J Neurosci 33, 17290-17300, doi:10.1523/JNEUROSCI.2619-13.2013 (2013). Wei, X., Nishi, T., Kondou, S., Kimura, H. \& Mody, I. Preferential enhancement of GluN2B-containing native NMDA receptors by the endogenous modulator 24S-hydroxycholesterol in hippocampal neurons. Neuropharmacology 148, 11-20, doi:10.1016/j.neuropharm.2018.12.028 (2019).

Maioli, S. et al. Is it possible to improve memory function by upregulation of the cholesterol 24S-hydroxylase (CYP46A1) in the brain? PloS one 8, e68534, doi:10.1371/journal.pone.0068534 (2013).

Mast, N. et al. Cholesterol-metabolizing enzyme cytochrome P450 46A1 as a pharmacologic target for Alzheimer's disease. Neuropharmacology 123, 465-476, doi:10.1016/j.neuropharm.2017.06.026 (2017).

Lund, E. G. et al. Knockout of the cholesterol 24-hydroxylase gene in mice reveals a brain-specific mechanism of cholesterol turnover. J Biol Chem 278, 22980-22988, doi:10.1074/jbc.M303415200 (2003). 
bioRxiv preprint doi: https://doi.org/10.1101/2021.10.18.462363; this version posted October 19, 2021. The copyright holder for this preprint (which was not certified by peer review) is the author/funder, who has granted bioRxiv a license to display the preprint in perpetuity. It is made available under aCC-BY-ND 4.0 International license.

114 Kotti, T. J., Ramirez, D. M., Pfeiffer, B. E., Huber, K. M. \& Russell, D. W. Brain cholesterol turnover required for geranylgeraniol production and learning in mice. Proceedings of the National Academy of Sciences of the United States of America 103, 3869-3874, doi:10.1073/pnas.0600316103 (2006).

115 Zoicas, I. \& Kornhuber, J. The Role of the N-Methyl-D-Aspartate Receptors in Social Behavior in Rodents. International journal of molecular sciences 20, doi:10.3390/ijms20225599 (2019).

116 Ripperger, S. P. et al. Vampire Bats that Cooperate in the Lab Maintain Their Social Networks in the Wild. Current biology : CB 29, 4139-4144 e4134, doi:10.1016/j.cub.2019.10.024 (2019).

117 Baron, G., Stephan, H. \& Frahm, H. D. Comparative Neurobiology in Chiroptera: Brain characteristics in functional systems, ecoethological adaptation, adaptive radiation, and evolution. (Springer, 1996).

118 Wang, C. C. et al. A critical role for GluN2B-containing NMDA receptors in cortical development and function. Neuron 72, 789-805, doi:10.1016/j.neuron.2011.09.023 (2011).

119 Kohl, S. et al. A nonsense mutation in PDE6H causes autosomal-recessive incomplete achromatopsia. Am J Hum Genet 91, 527-532, doi:10.1016/j.ajhg.2012.07.006 (2012).

120 Brennenstuhl, C. et al. Targeted ablation of the Pde6h gene in mice reveals cross-species differences in cone and rod phototransduction protein isoform inventory. J Biol Chem 290, 10242-10255, doi:10.1074/jbc.M114.611921 (2015).

$121 \mathrm{Li}$, L. et al. Retention and losses of ultraviolet-sensitive visual pigments in bats. Scientific reports 8, 11933, doi:10.1038/s41598-018-29646-6 (2018).

122 Kries, K. et al. Colour vision variation in leaf-nosed bats (Phyllostomidae): Links to cave roosting and dietary specialization. Mol Ecol 27, 3627-3640, doi:10.1111/mec.14818 (2018).

123 Sadier, A. et al. Multifactorial processes underlie parallel opsin loss in neotropical bats. eLife 7, doi:10.7554/eLife.37412 (2018).

124 Simoes, B. F. et al. As Blind as a Bat? Opsin Phylogenetics Illuminates the Evolution of Color Vision in Bats. Molecular biology and evolution 36, 54-68, doi:10.1093/molbev/msy192 (2019).

125 Chang, B. et al. A homologous genetic basis of the murine cpfl1 mutant and human achromatopsia linked to mutations in the PDE6C gene. Proceedings of the National Academy of Sciences of the United States of America 106, 19581-19586, doi:10.1073/pnas.0907720106 (2009).

126 Grau, T. et al. Decreased catalytic activity and altered activation properties of PDE6C mutants associated with autosomal recessive achromatopsia. Human molecular genetics 20, 719-730, doi:10.1093/hmg/ddq517 (2011). Emerling, C. A., Widjaja, A. D., Nguyen, N. N. \& Springer, M. S. Their loss is our gain: regressive evolution in vertebrates provides genomic models for uncovering human disease loci. J Med Genet 54, 787-794, doi:10.1136/jmedgenet-2017-104837 (2017).

128 Crespo, R. F., Linhart, S. B., Burns, R. J. \& Mitchell, G. C. Foraging Behavior of the Common Vampire Bat Related to Moonlight. Journal of Mammalogy 53, 366-368, doi:10.2307/1379175 (1972).

129 Groger, U. \& Wiegrebe, L. Classification of human breathing sounds by the common vampire bat, Desmodus rotundus. BMC Biol 4, 18, doi:10.1186/1741-7007-4-18 (2006).

130 Escalera-Zamudio, M. et al. The evolution of bat nucleic acid-sensing Toll-like receptors. Mol Ecol 24, 5899-5909, doi:10.1111/mec.13431 (2015).

131 Castillo, D. J., Rifkin, R. F., Cowan, D. A. \& Potgieter, M. The Healthy Human Blood Microbiome: Fact or Fiction? Front Cell Infect Microbiol 9, 148, doi:10.3389/fcimb.2019.00148 (2019).

132 Scarsella, E., Sandri, M., Monego, S. D., Licastro, D. \& Stefanon, B. Blood Microbiome: A New Marker of Gut Microbial Population in Dogs? Vet Sci 7, doi:10.3390/vetsci7040198 (2020).

133 Rademacher, F. et al. The Antimicrobial and Immunomodulatory Function of RNase 7 in Skin. Front Immunol 10, 2553, doi:10.3389/fimmu.2019.02553 (2019).

134 Eichler, T. E. et al. Insulin and the phosphatidylinositol 3-kinase signaling pathway regulate Ribonuclease 7 expression in the human urinary tract. Kidney Int 90, 568-579, doi:10.1016/j.kint.2016.04.025 (2016).

135 Rodriguez-Carlos, A. et al. Host Defense Peptide RNase 7 Is Down-regulated in the Skin of Diabetic Patients with or without Chronic Ulcers, and its Expression is Altered with Metformin. Arch Med Res 51, 327-335, doi:10.1016/j.arcmed.2020.03.006 (2020).

136 Rhie, A. et al. Towards complete and error-free genome assemblies of all vertebrate species. Nature 592, 737746, doi:10.1038/s41586-021-03451-0 (2021).

137 Protzek, A. O. et al. Insulin and glucose sensitivity, insulin secretion and beta-cell distribution in endocrine pancreas of the fruit bat Artibeus lituratus. Comparative biochemistry and physiology. Part A, Molecular \& integrative physiology 157, 142-148, doi:10.1016/j.cbpa.2010.05.016 (2010).

138 Michelmore, A. J., Keegan, D. J. \& Kramer, B. Immunocytochemical identification of endocrine cells in the pancreas of the fruit bat, Rousettus aegyptiacus. General and comparative endocrinology 110, 319-325, doi:10.1006/gcen.1998.7077 (1998).

139 Priyadarshini, M. \& Layden, B. T. FFAR3 modulates insulin secretion and global gene expression in mouse islets. Islets 7, e1045182, doi:10.1080/19382014.2015.1045182 (2015).

140 Hecker, N., Sharma, V. \& Hiller, M. Transition to an Aquatic Habitat Permitted the Repeated Loss of the Pleiotropic KLK8 Gene in Mammals. Genome Biol Evol 9, 3179-3188, doi:10.1093/gbe/evx239 (2017).

141 Sharma, V. \& Hiller, M. Loss of enzymes in the bile acid synthesis pathway explains differences in bile composition among mammals. Genome Biol Evol 10, 3211-3217, doi:10.1093/gbe/evy243 (2018).

142 Olson, M. V. When less is more: gene loss as an engine of evolutionary change. Am J Hum Genet 64, 18-23, doi:10.1086/302219 (1999). 
bioRxiv preprint doi: https://doi.org/10.1101/2021.10.18.462363; this version posted October 19, 2021. The copyright holder for this preprint (which was not certified by peer review) is the author/funder, who has granted bioRxiv a license to display the preprint in perpetuity. It is made available under aCC-BY-ND 4.0 International license.

143 Sikes, R. S., Animal, C. \& Use Committee of the American Society of, M. 2016 Guidelines of the American Society of Mammalogists for the use of wild mammals in research and education. J Mammal 97, 663-688, doi:10.1093/jmammal/gyw078 (2016).

144 Cheng, H., Concepcion, G. T., Feng, X., Zhang, H. \& Li, H. Haplotype-resolved de novo assembly using phased assembly graphs with hifiasm. Nature methods 18, 170-175, doi:10.1038/s41592-020-01056-5 (2021).

145 Ghurye, J. et al. Integrating Hi-C links with assembly graphs for chromosome-scale assembly. PLoS computational biology 15, e1007273, doi:10.1371/journal.pcbi.1007273 (2019).

$146 \mathrm{Li}, \mathrm{H}$. \& Durbin, R. Fast and accurate long-read alignment with Burrows-Wheeler transform. Bioinformatics 26, 589595, doi:10.1093/bioinformatics/btp698 (2010).

147 Kerpedjiev, P. et al. HiGlass: web-based visual exploration and analysis of genome interaction maps. Genome Biol 19, 125, doi:10.1186/s13059-018-1486-1 (2018).

148 Poplin, R. et al. A universal SNP and small-indel variant caller using deep neural networks. Nat Biotechnol 36, 983987, doi:10.1038/nbt.4235 (2018).

149 Harris, R. S. Improved pairwise alignment of genomic DNA Ph.D. Thesis thesis, The Pennsylvania State University, (2007).

150 Sharma, V. \& Hiller, M. Increased alignment sensitivity improves the usage of genome alignments for comparative gene annotation. Nucleic Acids Res 45, 8369-8377, doi:10.1093/nar/gkx554 (2017).

151 Kent, W. J., Baertsch, R., Hinrichs, A., Miller, W. \& Haussler, D. Evolution's cauldron: duplication, deletion, and rearrangement in the mouse and human genomes. Proceedings of the National Academy of Sciences of the United States of America 100, 11484-11489, doi:10.1073/pnas.1932072100 (2003).

152 Osipova, E., Hecker, N. \& Hiller, M. RepeatFiller newly identifies megabases of aligning repetitive sequences and improves annotations of conserved non-exonic elements. Gigascience 8, doi:10.1093/gigascience/giz132 (2019).

153 Suarez, H. G., Langer, B. E., Ladde, P. \& Hiller, M. chainCleaner improves genome alignment specificity and sensitivity. Bioinformatics 33, 1596-1603, doi:10.1093/bioinformatics/btx024 (2017).

154 Sharma, V., Schwede, P. \& Hiller, M. CESAR 2.0 substantially improves speed and accuracy of comparative gene annotation. Bioinformatics 33, 3985-3987, doi:10.1093/bioinformatics/btx527 (2017).

155 Sharma, V., Elghafari, A. \& Hiller, M. Coding exon-structure aware realigner (CESAR) utilizes genome alignments for accurate comparative gene annotation. Nucleic Acids Res 44, e103, doi:10.1093/nar/gkw210 (2016).

156 Frankish, A. et al. Gencode 2021. Nucleic Acids Res, doi:10.1093/nar/gkaa1087 (2020).

157 Foley, N. M., Springer, M. S. \& Teeling, E. C. Mammal madness: is the mammal tree of life not yet resolved? Philosophical transactions of the Royal Society of London. Series B, Biological sciences 371, doi:10.1098/rstb.2015.0140 (2016).

158 Lee, C. M. et al. UCSC Genome Browser enters 20th year. Nucleic Acids Res 48, D756-D761, doi:10.1093/nar/gkz1012 (2020).

159 Ranwez, V., Douzery, E. J. P., Cambon, C., Chantret, N. \& Delsuc, F. MACSE v2: Toolkit for the Alignment of Coding Sequences Accounting for Frameshifts and Stop Codons. Molecular biology and evolution 35, 2582-2584, doi:10.1093/molbev/msy159 (2018).

160 Di Franco, A., Poujol, R., Baurain, D. \& Philippe, H. Evaluating the usefulness of alignment filtering methods to reduce the impact of errors on evolutionary inferences. BMC Evol Biol 19, 21, doi:10.1186/s12862-019-1350-2 (2019).

161 Dobin, A. et al. STAR: ultrafast universal RNA-seq aligner. Bioinformatics 29, 15-21, doi:10.1093/bioinformatics/bts635 (2013).

162 Robinson, J. T. et al. Integrative genomics viewer. Nat Biotechnol 29, 24-26, doi:10.1038/nbt.1754 (2011). 